\title{
Detailed reconstruction of the nervous and muscular system of Lobatocerebridae with an evaluation of its annelid affinity
}

\author{
Alexandra Kerbl ${ }^{1}$, Nicolas Bekkouche ${ }^{1}$, Wolfgang Sterrer ${ }^{2}$ and Katrine Worsaae ${ }^{1 *}$
}

\begin{abstract}
Background: The microscopic worm group Lobatocerebridae has been regarded a 'problematicum', with the systematic relationship being highly debated until a recent phylogenomic study placed them within annelids (Curr Biol 25: 2000-2006, 2015). To date, a morphological comparison with other spiralian taxa lacks detailed information on the nervous and muscular system, which is here presented for Lobatocerebrum riegeri $\mathrm{n}$. sp. based on immunohistochemistry and confocal laser scanning microscopy, supported by TEM and live observations.

Results: The musculature is organized as a grid of longitudinal muscles and transverse muscular ring complexes in the trunk. The rostrum is supplied by longitudinal muscles and only a few transverse muscles. The intraepidermal central nervous system consists of a big, multi-lobed brain, nine major nerve bundles extending anteriorly into the rostrum and two lateral and one median cord extending posteriorly to the anus, connected by five commissures. The glandular epidermis has at least three types of mucus secreting glands and one type of adhesive unicellular glands.

Conclusions: No exclusive "annelid characters" could be found in the neuromuscular system of Lobatocerebridae, except for perhaps the mid-ventral nerve. However, none of the observed structures disputes its position within this group. The neuromuscular and glandular system of L. riegeri $\mathrm{n}$. sp. shows similarities to those of meiofaunal annelids such as Dinophilidae and Protodrilidae, yet likewise to Gnathostomulida and catenulid Platyhelminthes, all living in the restrictive interstitial environment among sand grains. It therefore suggests an extreme evolutionary plasticity of annelid nervous and muscular architecture, previously regarded as highly conservative organ systems throughout metazoan evolution.
\end{abstract}

Keywords: Nervous system, Musculature, Glandular system, Meiofauna, Annelida, Spiralia, CLSM, Immunohistochemistry, Ultrastructure

\section{Background}

Although phylogenomic studies have increased our knowledge of metazoan phylogeny significantly [1-4], a few 'Problematica' $[5,6]$ remain unplaced. Chief among those is the interstitial family Lobatocerebridae, which a recent phylogenetic study based on transcriptomic data positioned within Annelida, as sister group to Sipuncula, albeit with moderate support [7]. This enigmatic group of microscopic, thread-like, fully ciliated animals with glandular epidermis, living interstitially between sand

\footnotetext{
* Correspondence: kworsaae@bio.ku.dk

1 Marine Biological Section, Department of Biology, University of

Copenhagen, Universitetsparken 4, 1st floor, 2100 Copenhagen E, Denmark

Full list of author information is available at the end of the article
}

grains in the subtidal sandy sea-floor, was described as its own family, Lobatocerebridae, with one species, Lobatocerebrum psammicola [8]. The morphological data available have never indicated a relationship to Sipuncula, although affinities to Annelida as well as to Platyhelminthes have been debated $[8,9]$. Due to the ambiguity of the morphological features pointed out by Rieger [8-11], this group was suggested to be its own phylum Lobatocerebromorpha in 1991, alongside annelids, platyhelminthes, molluscs and other spiralians $[6,12]$; a status now denied by the recent phylogenomic analyses [7].

Lobatocerebrum psammicola was described from the shallow waters off the Coast of North Carolina, USA, based on TEM and LM section series [8-11]. The same 
articles mention two additional undescribed species from the deep waters off North Carolina and from Eilat, Israel, respectively [8-10]. Additional specimens have been recorded by various authors from marine localities in the Atlantic (for example in Denmark [13], Gran Canaria (Spain) and Elba (Italy, W. Sterrer unpublished), and the Atlantic coast of Panama [7]), but the detailed morphology or taxonomy of these animals (besides $L$. psammicola) has never been investigated. Lobatocerebridae are found in subtidal marine habitats with coarse sand mixed with fine silt, but with limited organic and terrestrial matter. Although found at shallow depths, they are never abundant, and may be mistaken for platyhelminthes, juvenile nemerteans or gnathostomulids, which might explain their understudied nature and lack of additional records. Due to the inaccessibility of material, the explicit descriptions given by R. Rieger in his series of articles [8-11] have remained the only source for systematic and evolutionary discussions for decades $[5,6,12,14]$.

Lobatocerebrids have been described by Rieger [8-10] as having a thin, elongated body with circular cross section and complete ciliation. The epidermis is furthermore interspersed with a high number of unicellular glands. The ventral mouth opening is located one-third of the length from the tip (delineating the rostrum from the trunk), the dorsal male gonopore is positioned twothirds of the length from the tip, followed by one to several lateral openings of the seminal receptacles in the posterior end of the body and the subterminal dorsal anus. The most prominent and also eponymous character of the animal is the large, multi-lobed brain, which is located anterior to the mouth opening, nearly taking up the entire cross section of the animal. The intraepidermal, ventral nervous system is reported to consist of two lateral nerve cords and two postpharyngeal commissures. The body wall musculature was described as outer longitudinal and inner circular muscles. The animals are simultaneous hermaphrodites [8-10]. Still, none of these morphological characteristics have made a clear classification into or next to one of the existing nominal phyla possible at the end of the $20^{\text {th }}$ century since the identification of common traits has been ambiguous. However, especially Annelida, Gastrotricha, Gnathostomulida, Mollusca, Nemertea, and Platyhelminthes have been discussed as most likely relatives $[6,8,11,12]$. Details of the epidermis and other characters were examined by Rieger [8-11] with ultrathin $(40-70 \mathrm{~nm})$ sections and transmission electron microscopy (TEM), providing information of great ultrastructural detail. However, a detailed cohesive analysis of several organ systems throughout the entire body, including the complete nervous and muscular system mapped with immunostaining and confocal microscopy is still warranted. This will not only enhance our understanding of their morphology but also facilitate a comparison with morphological data on other interstitial groups gathered within the last two decades [15-17].

Both muscular and nervous systems have been assumed to represent rather conserved organ systems when it comes to their general architecture [18]. Annelids, however, have been found to be highly diverse in their morphological characters, and the ancestral states of musculature $[19,20]$ and nervous system [21] are still debated. The muscular layout in Lobatocerebridae has been described as internal circular and external longitudinal muscles $[8,10]$, which contradicts the arrangement found in the majority of annelids [22, 23]. However, cases are known where external circular muscles are reduced [24, 25] and several other muscle sets such as transverse, dorsoventral or bracing muscles have been proposed to functionally represent the circular muscles [22]. Nervous system organization has been suggested to be of high systematic importance, revealing synapomorphies of larger clades within e.g., Crustacea [26], which may be undetectable within other organ systems [21, 27, 28]. However, the nervous system in Annelida varies between being intraepidermal to subepidermal [29], in the number of commissures in the brain (2-4, [29]), the number of circumesophageal commissures (1-2, [29]), the number and arrangement of ventral nerve cords (1-7, medio- to lateroventral $[15,21,29])$ and the number and arrangement of commissures in the ventral nervous system (regularly and mid-segmental to irregularly spread along the entire ventral nervous system $[15,21,29]$ ). Based on the previously available information $[8,10]$ none of the few characteristics of the musculature or nervous system of Lobatocerebridae could be ascribed to annelids only, since they also show similarities to the pattern described especially from interstitial Gnathostomulida, Plathelminthes, and Mollusca [6, 8-10].

Lobatocerebridae belongs to the meiofauna (animals between $2 \mathrm{~mm}$ and $0.06 \mathrm{~mm}$ in size [16]), together with exclusively microscopic lineages such as Gastrotricha, Acoelomorpha, Rotifera, Gnathostomulida, Platyhelminthes (except for parasitic forms), Tardigrada, Loricifera, Kinorhyncha, as well as miniaturized forms of macrofaunal lineages such as Annelida, Mollusca and Crustacea $[16,30,31]$. The apparent lack of distinct morphological synapomorphies with other clades, the presence of many autapomorphies, and the inaccessibility of material are the main reasons for why the phylogenetic positioning of these interstitial lineages has been so challenging; and why we only most recently have obtained more information on their evolution [7, 32, 33]. Interstitial fauna (living in the interstices between sand grains) all have a microscopic diameter size and most forms are also categorized as meiofaunal. Besides their small size, these interstitial animals often display simple-looking, 
worm-like, highly ciliated and glandular, acoelomate bodies with no or few appendages; traits that generally seem to be favored in their confined interstitial environment [16, 34-36]. Several of these seemingly shared traits of interstitial fauna may either have originated as convergent adaptations to their restrictive environment and size, or reflect the recently proposed ancestral meiofaunal condition of Spiralia [7]. Hence, new detailed anatomical investigations of Lobatocerebridae should be evaluated in comparison not only with Annelida, discussing heritage and character evolution, but also with other relevant interstitial metazoans, in order to uncover possible convergent anatomical adaptations to the interstitial space-restricted environment.

The present study will evaluate the recent molecular placement of Lobatocerebridae within Annelida [7], in the light of detailed morphological investigation of nervous, muscular and glandular system with state-of-theart immunohistochemistry in combination with confocal laser scanning microscopy (CLSM) and transmission electron microscopy (TEM). Hereby, we attempt to unravel and discuss possible resemblances with relevant interstitial spiralians, and whether these common traits may represent annelid synapomorphies, annelid or spiralian plesiomorphies, or convergent adaptations to the space restricted interstitial environment. Furthermore, with the description of Lobatocerebrum riegeri n. sp., we are adding another species to this enigmatic, otherwise monotypic group.

\section{Results}

Specimens of Lobatocerebrum riegeri n. sp. overall resemble the body plan described by Rieger [8] for Lobatocerebrum psammicola. More details of the nervous, muscular and glandular systems could be detected in this study, as described in the following (Figs. 1, 2, 3, 4, $5,6,7,8,9)$.

\section{Musculature}

Examined in live and preserved specimens in LM; with phalloidin staining in CLSM and ultrathin sections in TEM; Figs. 1, 2.

\section{Body wall}

Longitudinal musculature As observed by Rieger $[8,10]$, all muscles of Lobatocerebridae are smooth muscles (confirmed by both CLSM and TEM); no striated musculature was detected in the present study. The longitudinal musculature is organized in six pairs of loose bundles, extending from the rostral tip to the posteriormost end of the body (Figs. 1, 2a-h). Five pairs of these, the dorsal (dlm), dorsolateral (dllm), two pairs of lateral (llm) and one pair of ventrolateral muscle bundles (vllm), lie dorsal to the two prominent ventral nerve cords, whereas the ventral longitudinal muscles are located ventral to those (Fig. 1a-g). Each of these muscle bundles consists of three to five muscle fibres (Fig. 2a-f) and has a diameter of 1.2-2.4 $\mu \mathrm{m}$ (measurements based on: number of specimens $(n)=3$, region of body $(r)=1-4$, measurements $(m)=5$ ), deeply embedded into the epidermal cells distal to the transverse muscular ring complexes (see below, tmr). The twelve bundles are regularly distributed along the entire body length (spaced 7.2-10.1 $\mu \mathrm{m}$ apart, $n=3, r=1-4, m=$ 5, Figs. $1 \mathrm{~b}-\mathrm{g}, 2 \mathrm{a}-\mathrm{e}$ ), except around the mouth opening, where the ventralmost pair (vlm) is shifted closer to the adjacent ventrolateral pair (vllm). The male gonopore or the openings of the seminal receptacles do not cause any similar distortions. All twelve longitudinal muscle bundles extend to the posterior end of the body, inserting subterminally around the anus. While the dorsal, dorsolateral and lateral muscles insert directly, the ventrolateral and ventral bundles first trace the epidermis to the terminal end, before bending antero-dorsally and inserting subterminally around the anus (Fig. 2c).

Transverse muscular ring complexes Transverse muscular ring complexes (tmr) are distributed in a regular pattern (spaced 14.5-16.9 $\mu \mathrm{m}$ apart) from the pharynx to the ovary (Fig. 2a), and spaced $6.8-8.9 \mu \mathrm{m}$ apart posterior of the ovary to the sixth sphincter $(n=3, r=2,3$, $m=5$, Figs. $1,2 \mathrm{~b}-\mathrm{c}$ ). They have previously been misidentified as internal circular musculature [8]. This study, however, could detect that each muscular ring is formed by a series of individual transverse muscle fibres (diameter $0.8-1.3 \mu \mathrm{m}, n=3, r=2,3, m=5$ ); each of them only spanning the distance between one to three longitudinal bundles (7.6-35.7 $\mu \mathrm{m}, n=3, r=2,3, m=5$, Fig. 2j). Up to nine individual transverse fibres are found to constitute one transverse muscular ring complex between all 12 longitudinal muscles (Fig. 2i-j).

Transverse muscles do not form transverse muscular ring complexes in the rostrum, but instead appear as contralateral fibres between longitudinal muscle bundles of opposite sides of the body, hereby creating a star-like structure of individual fibres (star-shaped muscles, ssm, diameter of individual fibres $0.5-1.1 \mu \mathrm{m}$, length 10.5$45.2 \mu \mathrm{m}, n=3, r=1, m=5$, Fig. 2d, g-h). Their abundance is highest close to the rostral tip (spaced 2.4-5.7 $\mu \mathrm{m}$ apart, $n=2, r=1, m=5$ ), where the ducts of the posterior frontal glands are ramifying, and farther separated towards the middle region of the rostrum (spaced 10.3$20.6 \mu \mathrm{m}$ apart, $n=2, r=1, m=5$, Fig. $2 \mathrm{~g}-\mathrm{h}$ ). The glandular ducts are not muscularized and no closing or constricting mechanism could be detected in this or previous studies $[8,9,11]$. The transverse muscles might therefore be involved in regulating the flow of 


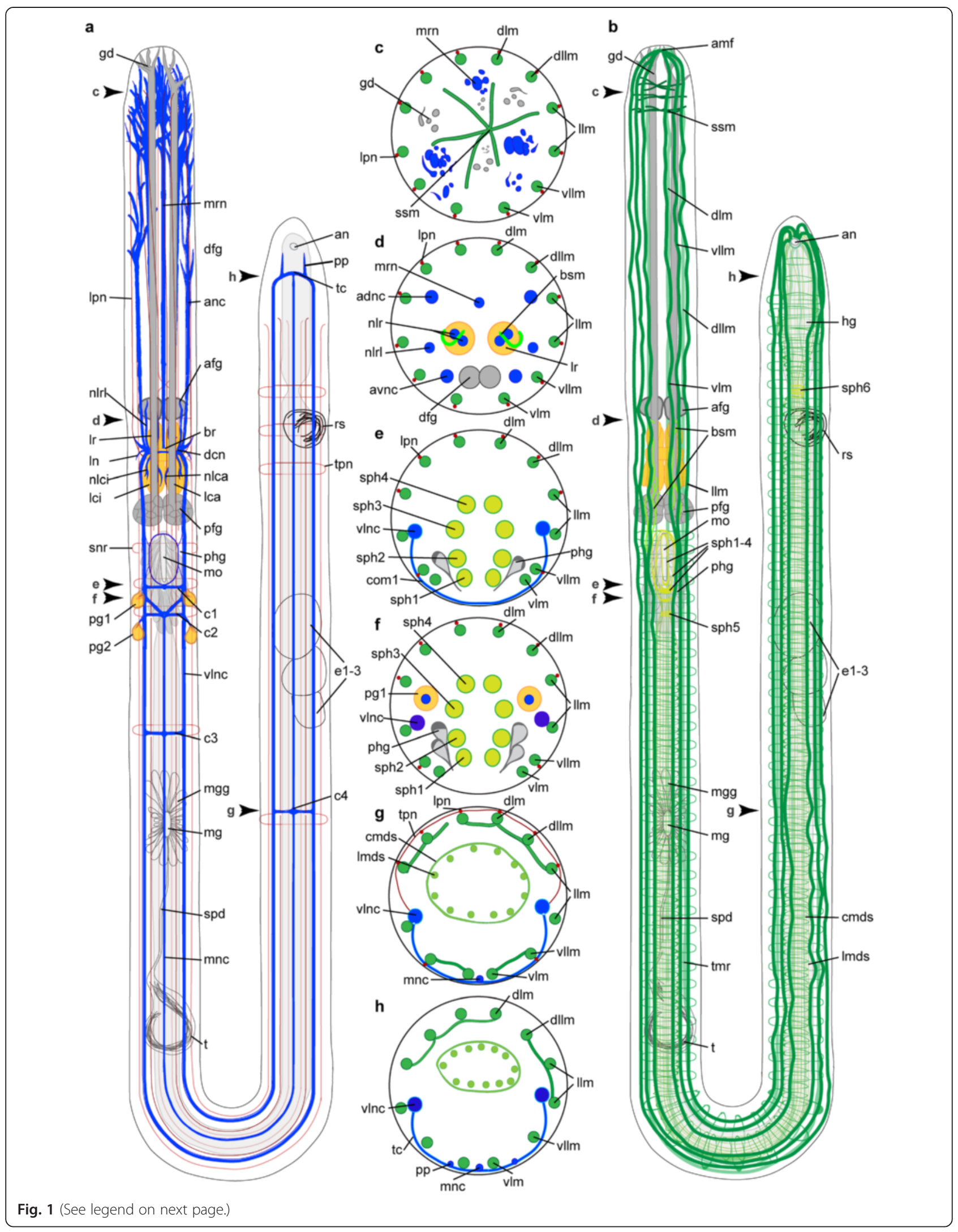


(See figure on previous page.)

Fig. 1 Anatomy of Lobatocerebrum riegeri n. sp. as inferred from immunohistochemistry and CLSM. Information is based on all specimens investigated and all antibodies used. a Nervous system $\mathbf{b}$ Musculature, $\mathbf{c}-\mathbf{g}$ cross sections in the middle of the rostrum (c), at the level of the anterior end of the rostral lobes (d), at the level of the first commissure posterior to the pharynx of L. riegeri n. sp. (e), between the first and the second commissure $(\mathbf{f})$, at the level of the forth commissure $(\mathbf{g})$ and the level of the subrectal commissure (h). Abbreviations: adnc: anterior dorsal nerve cord, afg: anterior frontal gland, amf: anterior point of muscle fusion, an: anus, anc: anterior nerve cord, br: brain, bsm: brain supporting muscle, c1-4: commissures 1-4, cmds: circular muscle of the digestive system, dcn: dorso-anterior commissure of the central neuropil, dfg: frontal gland ducts, dllm: dorsolateral longitudinal muscle, dlm: dorsal longitudinal muscle, e1-3: egg 1-3, gd: opening of the frontal glands, hg: hindgut, Ica: major caudal lobe, Ici: minor caudal lobe, IIm: lateral longitudinal muscle, Imds: longitudinal muscle of the digestive system, In: lateral nerve, Ipn: lateral peripheral nerve, Ir: rostral lobe, Irl: lateral rostral lobe, mg: male gonopore, mgg: male gonopore gland, mnc: median nerve cord, mo: mouth opening, mrn: median rostral nerve, nlca: nerve of the major caudal lobe, nlci: nerve of the minor caudal lobe, nlrl: nerve of the lateral rostral lobe, nlr: nerve of the major rostral lobe, pfg: posterior frontal gland, pg1-2: postpharyngeal ganglion 1-2, phg: pharyngeal gland, pp: posterior projection, rs: seminal receptacles, snr: stomatogastric nerve ring, spd: spermioduct, sph1-6: sphincter 1-6, ssm: star-shaped muscle, t: testis, tc: terminal commissure, tmr: transverse muscle ring complex, tpn: transverse ring of the peripheral nervous system, vllm: ventrolateral longitudinal muscle, vlm: ventral longitudinal muscle, vlnc: ventral longitudinal nerve cord

secretion, in addition to enhancing the flexibility of the rostral tip as observed by behavioral observations (Additional file 1).

Additional minor body muscles Specific musculature is formed around the brain, emerging from the ventral and ventrolateral muscles around the pharynx and extending towards the anterior. The lateral pair of these muscles extends lateroventral to the brain, where the fibres branch off around or into the frontal lobe complex (Figs. 1b, 2e-f). The median pair extends to the caudal lobes, where they branch off into more individual fibres and lead to the major, minor and lateral caudal lobes (Figs. 1b, 2e). Due to the intricate network hereby formed around the anterior and posterior regions of the brain, we suggest these muscles to be a supportive structure for the brain, which is probably necessary due to a lack of other structures securing its position in the rostrum.

\section{Intestinal musculature}

Pharynx Although lacking a ventral or axial muscle bulb as found in most annelids, the pharynx is still the most prominent muscular structure in the body, showing five sphincter muscles as already defined by Rieger [8] in addition to the longitudinal body and gut musculature. The first four sphincter muscles of the pharynx surround the mouth opening and mouth cavity (sph1-sph4, adapted from Rieger's sph0-3 [8]), while the fifth sphincter constricts the digestive tract in the transversal plane, as a short esophagus delineating the pharynx from the midgut (sph5, Figs. 1b, 2a, i-j). Sphincters 1-4 consist of two to three fibres each (diameter 0.7-1.6 $\mu \mathrm{m}$ ), which are always external to the longitudinal muscles of the digestive tract (Fig. 2j). The fifth sphincter (sph5), however, consists of up to eight thin, serially aligned, muscle fibres (diameter 1.2-1.5 $\mu \mathrm{m}, n=3, r=2, m=5)$. It marks the border to the midgut through an elongated constriction to a diameter of
4.5-4,98 $\mu \mathrm{m}$ when relaxed $(n=3, r=2, m=5$, Figs. $1 \mathrm{~b}$, $2 a, j)$. Additionally, the individual fibres are interwoven with the longitudinal gut muscles, rather than being located externally of these (Fig. 2j).

Digestive tract The intestinal musculature consists of 12 to 16 individual longitudinal fibres (lmds, diameter 0.66-0.74 $\mu \mathrm{m}, n=3, r=2,3,4, m=5)$ arranged in equal distance from each other (spaced 1.5-3.1 $\mu \mathrm{m}$ apart, $n=3, r=2,3,4, m=5$ ), and therefore resembling the muscular pattern of the body wall musculature (Fig. 2a, i). The circular muscles of the digestive system (cmds), however, are arranged external to the longitudinal muscles of the gut (Fig. 2a, j), as is typical for gut musculature. These true circular muscles (as compared to the transverse muscular ring complexes) are very thin (diameter 0.5-0.6 $\mu \mathrm{m}$, spaced 3.1-5.8 $\mu \mathrm{m}$ apart, $n=3, r=2,3,4, m=5)$ and most consistent in the pharyngeal region anterior and posterior to the fifth sphincter. In the posterior part of the body the longitudinal muscle fibres are embraced by the sixth, last sphincter, which consists of two short circular fibres (diameter 1.35-2.1 $\mu \mathrm{m}, n=3, r=4, m=3$ ) and constricts the digestive tract to $6.4-6.6 \mu \mathrm{m}$ when relaxed $(n=$ $3, r=4, m=4$, Fig. 2c). The longitudinal muscles of the digestive system fuse with the longitudinal muscles posterior to this constriction (Fig. 2c).

\section{Nervous system}

Visualized with acetylated $\alpha$-tubulin IR, serotonin IR, FMRFamide-like IR, DAPI for cell nuclei and CLSM, Figs. 1, 2, 3, 4, 5, 6, 7 .

The brain in the rostrum of Lobatocerebrum riegeri $\mathrm{n}$. sp. is the most conspicuous part of the central nervous system. A series of both anterior rostral and posterior trunk nerve cords emerges from the central neuropil, and some additional nerve bundles are found branching off laterally to the brain (Fig. 4). The brain was described as having one pair of lobes anterior to the neuropil (rostral lobes) and two pairs of lobes (major and minor caudal 


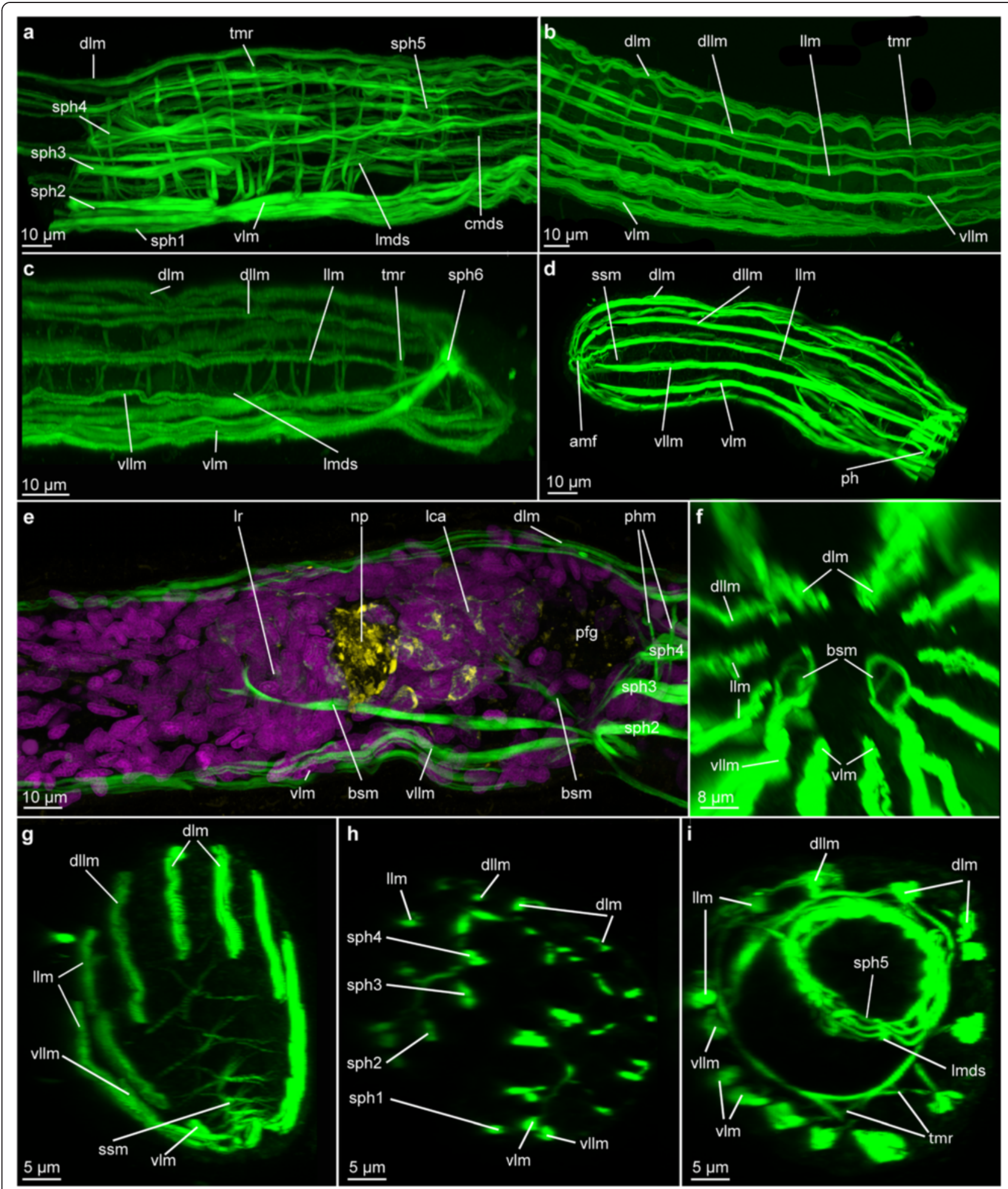

Fig. 2 (See legend on next page.) 
(See figure on previous page.)

Fig. 2 Muscular architecture in Lobatocerebrum riegeri n. sp. as seen with CLSM. Musculature (actin-filaments) in green, DAPI in purple, acetylated alpha-tubulin in yellow. $\mathbf{a}, \mathbf{d}, \mathbf{g}$ and $\mathbf{h}$ ) Maximum intensity projections of a juvenile specimen, $\mathbf{b}, \mathbf{c}, \mathbf{e}, \mathbf{f}$ and $\mathbf{i}$ ) Maximum intensity projections of adult specimens. If not indicated otherwise, anterior is to the left and dorsal is up. a Lateral view of the body wall and digestive system musculature in pharyngeal area with sphincters, $\mathbf{b}$ Lateral view of the body wall musculature in the median region (between the male gonopore and the female ovary), $\mathbf{c}$ Lateral view of the body wall and digestive system musculature in the posterior tip of the animal, $\mathbf{d}$ Lateral view of the musculature in the anterior tip, e Lateral view of the anterior region of the body wall musculature in a virtually cropped image stack, revealing the brain supporting musculature, $\mathbf{f}$ Virtual view from inside of the animal towards the anterior tip posterior to the anterior portion of the brain supporting muscles, $\mathbf{g}$ Virtually cropped view of an anterior tip with star-shaped muscles, $\mathbf{h}$ Virtual transverse section through the pharynx with sphincters 1-4, i Virtual transverse section at the level of sphincter 5. Abbreviations: amf: anterior point of muscle fusion, bsm: brain supporting muscle, cmds: circular muscle of the digestive system, dllm: dorsolateral longitudinal muscle, dlm: dorsal longitudinal muscle, Ica: major caudal lobe, IIm: lateral longitudinal muscle, Imds: longitudinal muscle of the digestive system, Ir: rostral lobe, np: neuropil, pfg: posterior frontal gland, ph: pharynx, sph1-6: sphincter 1-6, ssm: star-shaped muscle, tmr: transverse muscle ring complex, vllm: ventrolateral longitudinal muscle, vlm: ventral longitudinal muscle

lobes [8]) posterior to it. However, this study reveals a more complex system of several sublobes both in the anterior and posterior region (Fig. 4a, b). A total of four main commissures in the ventral nervous system (two posterior to the pharynx, one approximately half way between the pharynx and the male gonopore, one anterior to the ovary) are recognized. The anterior two commissures, associated with ganglia, connect the two lateral and the median posterior nerve cords with each other (Figs. 1a, c-g, 4a-c, e). The three longitudinal ventro-posterior cords fuse forming a subrectal commissure. Additionally, peripheral nerves are embedded in the epithelial layer of the animal, forming a grid of longitudinal and semicircular to circular nerves being perpendicular to each other, and being related to the central nervous system.

\section{Acetylated a-tubulin-IR}

Central nervous system: Brain The brain of Lobatocerebrum riegeri n. sp. consists of a large neuropil surrounded by impressive multi-lobed groups of perikarya from where longitudinal nerves extend laterally, anteriorly and posteriorly (Figs. 4, 5). The central neuropil comprises several commissures, which seem to be connecting the two main ventral cords in a pattern possibly resembling the annelid dorsal and ventral root of the circumesophageal commissure. The dorsal, median and ventro-anterior commissures are constituted as well defined nervous bundles, consisting of more than 40 nerve fibres. The ventroposterior commissures cannot always be resolved as individual structures, but form a thin sheath of nervous fibres (Figs. 3d, f, 4).

At least three pairs of characteristic large lobes (or ganglia) are arranged around the central neuropil, namely the paired anterior rostral lobes anterior to the neuropil and the pairs of posterior major and minor caudal lobes (respectively lca and lci, Figs. 3a-b, 4b, 5b-d). The major caudal lobes (lobus caudalis major according to Rieger [8], lca) are located mid-ventrally between the minor caudal lobes (lobus caudalis minor according to Rieger [8], lci, Figs. 3a, $4 a-b, 5 b-d)$. The minor caudal lobes seem to be subdivided into a lateral and a median sublobe (lcil and lcim, respectively, Fig. 4b). No postcerebral ganglia as described by Rieger [8] have been found, suggesting that either the lateral sub-lobes of the minor caudal lobes or the lateral ganglia, which were found lateral to the central neuropil, have been mistaken for a postcerebral ganglion by Rieger [8]. The rostral lobes (lobus rostralis according to Rieger [8]) appear to be subdivided into one major (lra) and one minor portion (lri) and one lateral sublobe (lrl, Fig. 4a-b).

Although the nervous network of the neuropil is complex and intricate, some major connections could be reconstructed by means of CLSM. Four paired and one unpaired anteriorly directed rostral nerves all originate independently, but adjacent to each other from the anterolateral parts of the neuropil. In addition, several short nerves project out ventrolaterally from the neuropil for 10 to 20 micrometers (lpnp, Figs. 4a-b, 5d). However, no putative specific structure innervated by them could be identified in that region. The four paired and one unpaired rostral nerves anterior to the brain comprise: 1) One pair of ventrolateral anterior nerve cords extending ventro-laterally from the anterior neuropil (avnc, Figs. 3a, d-f, 5d) as an anterior extension of the posterior main ventral cords. Each of the ventrolateral anterior cords splits into two thinner bundles to innervate the tip and the sides of the rostrum (avnc and avlns, respectively, Fig. 4a-b). 2) One pair of dorsolateral nerves splitting up anteriorly (adnc, adlnc, Fig. 4a-b) originating from the lateral neuropil and possibly connected to the nerve stems of the major caudal lobes. 3) One pair of lateral nerve bundles (nlrl, Fig. 4a-d) originating dorsomedially at the dorsal root commissure but bending ventrolaterally between the lateral and anterior rostral lobes, where after they condense into a thick bundle continuing ventrolaterally throughout the rostrum until they fan out in the anterior end. 4) One loose pair of nerve bundles (nlr, Figs. 3d, 4, 5b-c) originating from the anterolateral 

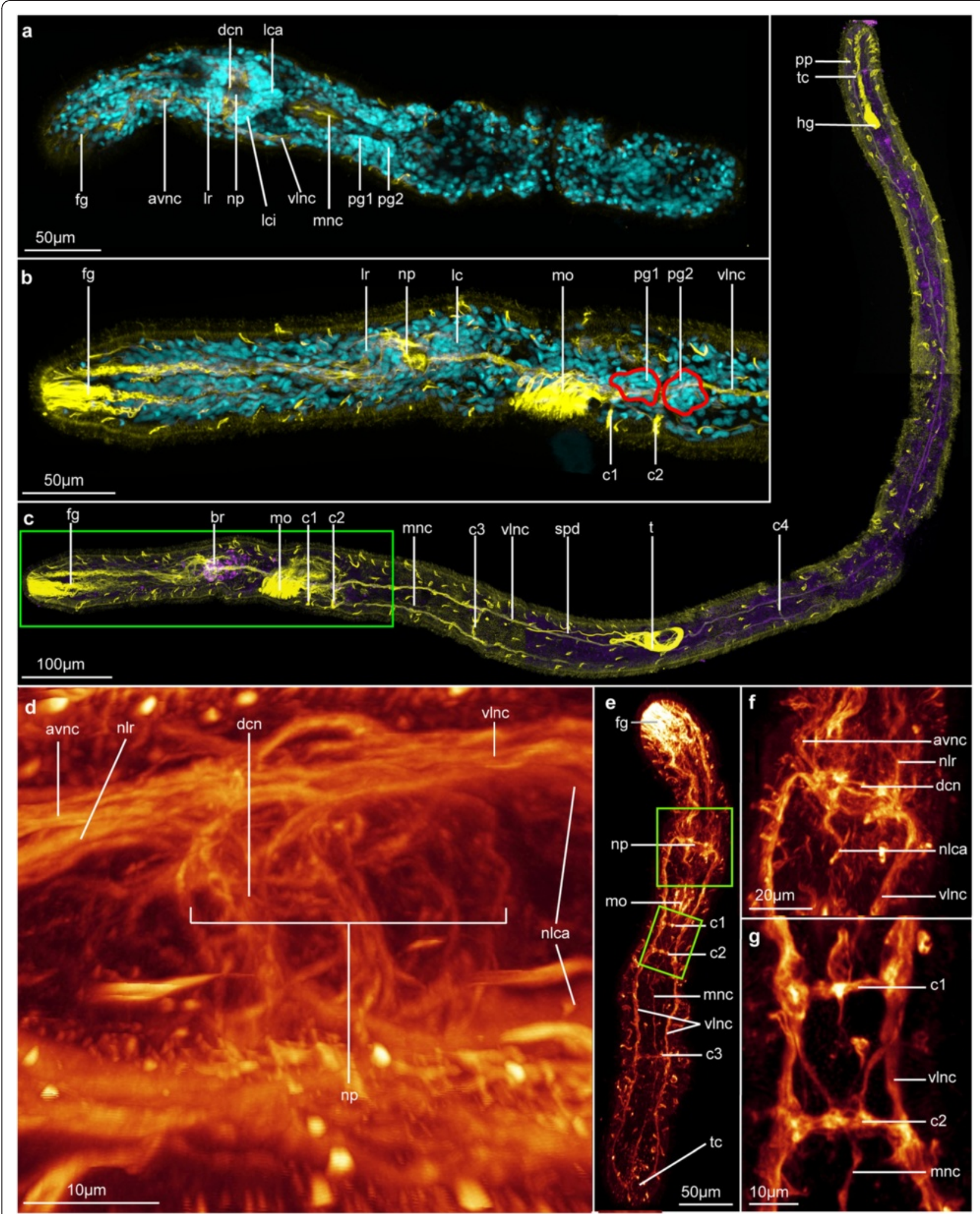

Fig. 3 (See legend on next page.) 
(See figure on previous page.)

Fig. 3 General and detailed organization of the nervous system of Lobatocerebrum riegeri n. sp. as seen with CLSM. DAPI in cyan, FMRF in purple and acetylated a-tubulin in yellow or "glow". All images are maximum intensity projections of a subset of the original image stack on various locations of the body if not specified below a Dorsal view of a juvenile specimen, $\mathbf{b}$ Lateral view of an adult, pharyngeal ganglia outlines in red, details of the same specimen as (c), c Three different substacks of an adult specimen pieced together for an overview-picture. The specimen is twisted and some portions are laterally oriented and others dorso-ventrally oriented, $\mathbf{d}$ Dorsal view of the details of the brain, e Juvenile showing the general organization of the nervous system. Notice the presence of only three trunk commissures, $\mathbf{f}$ Dorsal view of the details of the brain in a juvenile. Details of the same specimen as (e), $\mathbf{g}$ Dorsal view of details of the origin of the median nerve cord in a juvenile. Details of the same specimen as (e). Abbreviations: avnc: anterior ventral nerve cord, br: brain, c1-4: commissure 1-4, dcn: dorso-anterior commissure of the neuropil, fg: frontal gland, hg: hindgut, Ic: caudal lobe, Ica: major caudal lobe, Ici: minor caudal lobe, Ir: rostral lobe, mnc: median nerve cord, mo: mouth opening, nlca: nerve of the major caudal lobe, nlr: nerve of the rostral lobe, np: neuropil, pfg: posterior frontal glands, pg1-2: postpharyngeal ganglia 1 - 2, pp: posterior projection, spd: spermioduct, t: testes, tc: terminal commissure, vinc: posterior ventro lateral nerve cord

neuropil with minor subbundles (nlri and nlra, respectively, Fig. 4a-d) leading medioventrally through the major and minor rostral lobes, joining anteriorly of these, and continuing into the anterior part of the rostrum, before spreading out. 5) One unpaired median nerve ( $\mathrm{mrm}$ ) originating middorsally from the dorsal commissure (dc) between the two rostral lobes and extending dorsally through the entire rostrum, until it eventually splits at the tip to innervate the anterior edge (Figs. $4 a-d, 5 b-c)$. The function of such a strong innervation of the rostrum is unknown. However, some nerves connect directly to specific cilia, which are stiff and longer than the locomotory cilia and therefore assumed to have sensory function. Many nerves, however, do not seem to connect to any specific epidermal structures and no multicellular sensory organ could be found. Posterior to the neuropil, two pairs of thick dorso-posterior nerve stems extend posteriorly into the major (nlca) and minor caudal lobes (nlci, Fig. 4a-d); again branching into the two median and lateral parts of the minor lobes (nlci and nlcil, respectively, Fig. 4a-d). The nerve stem of each major caudal lobe is composed of nerves originating from the dorsal commissure (which is suggested to resemble the dorsal commissure of the dorsal root) as well as lateral nerves of the neuropil, the latter being seemingly continuous with the rostral dorsolateral nerves. If truly continuous, this may indicate that the dorsolateral nerves are sensory nerves transferring sensory inputs from the rostrum to be processed in the major caudal lobes.

Central nervous system: Ventral cords and commissures In all specimens investigated, the posterior parts of the ventrolateral nerve cords emerge from the ventrolateral area of the central neuropil and extend to the terminal commissure anterioventral to the anus (pc, Figs. 3c, e). They are located dorsolateral to the third (lateral) muscle bundle, although this position varies slightly throughout the body, with the longitudinal muscles sometimes being so deeply embedded within the epidermis that they become more externally positioned than the nerve cords (Fig. 1e-h). The ventrolateral nerve cords consist of three to four times more fibres than the median nerve and measure $3-4 \mu \mathrm{m}$ in diameter. The longitudinal ventromedian nerve is located intraepidermally, between the two most ventral longitudinal muscle bundles (mnc, Fig. 3g). It is formed by contralateral projections of the ventrolateral nerve at the level of the first commissure, which fuse in the ventral midline with their counterpart at the level of the second commissure. Hereafter, the median nerve continues posteriorly to insert at the terminal commissure. Two projections from the terminal commissure extend for $10-15 \mu \mathrm{m}$ dorso-posteriorly (pp, Fig. 3c).

Four trunk commissures are connecting the two ventrolateral nerve cords and the median nerve with each other (c1-4, Figs. 1a, c-h, 3b-c, e, 5a). Each commissure apparently consists of as many nerve fibres as the ventro-lateral cords and measures $3-4 \mu \mathrm{m}$ in diameter. The anteriormost two commissures are located close to each other posterior to the mouth opening, separated by $20-25 \mu \mathrm{m}$ (c1, c2, Figs. 1a and 3e, g). Since few of the perikarya of the commissures were showing immunoreactivity against serotonin or FMRFamide, only the large ganglia of the first and second commissures could be detected by a few serotonergic cells and DAPIstaining, here showing densely grouped nuclei (Fig. 5a, e). These ganglia are situated dorsoposterior to the commissures and each consists of 30-40 cells (pg1-2, Figs. 3a, b and $5 \mathrm{e}$ ). The third commissure is located between the pharynx and the male gonopore, approximately 30-50 $\mu \mathrm{m}$ anterior to the gonopore (c3, Fig. 3c). The fourth commissure (c4, Fig. 3c) is located between the testis and ovary.

Single, presumably sensory, cells are sparsely distributed throughout the epidermis of the entire body, but connect to neither the ventral nerve cords nor the peripheral nerves (ss, Fig. 5f). Normally, they consist of one cell with a single cilium often surrounded by a circle of microvilli (Fig. 5f). There is no correlation between a high abundance of these sensoria and specific organs or body regions.

Peripheral nervous system The peripheral nervous system is embedded in the epidermal cell layer and consists of longitudinal and incomplete circular fibres. 


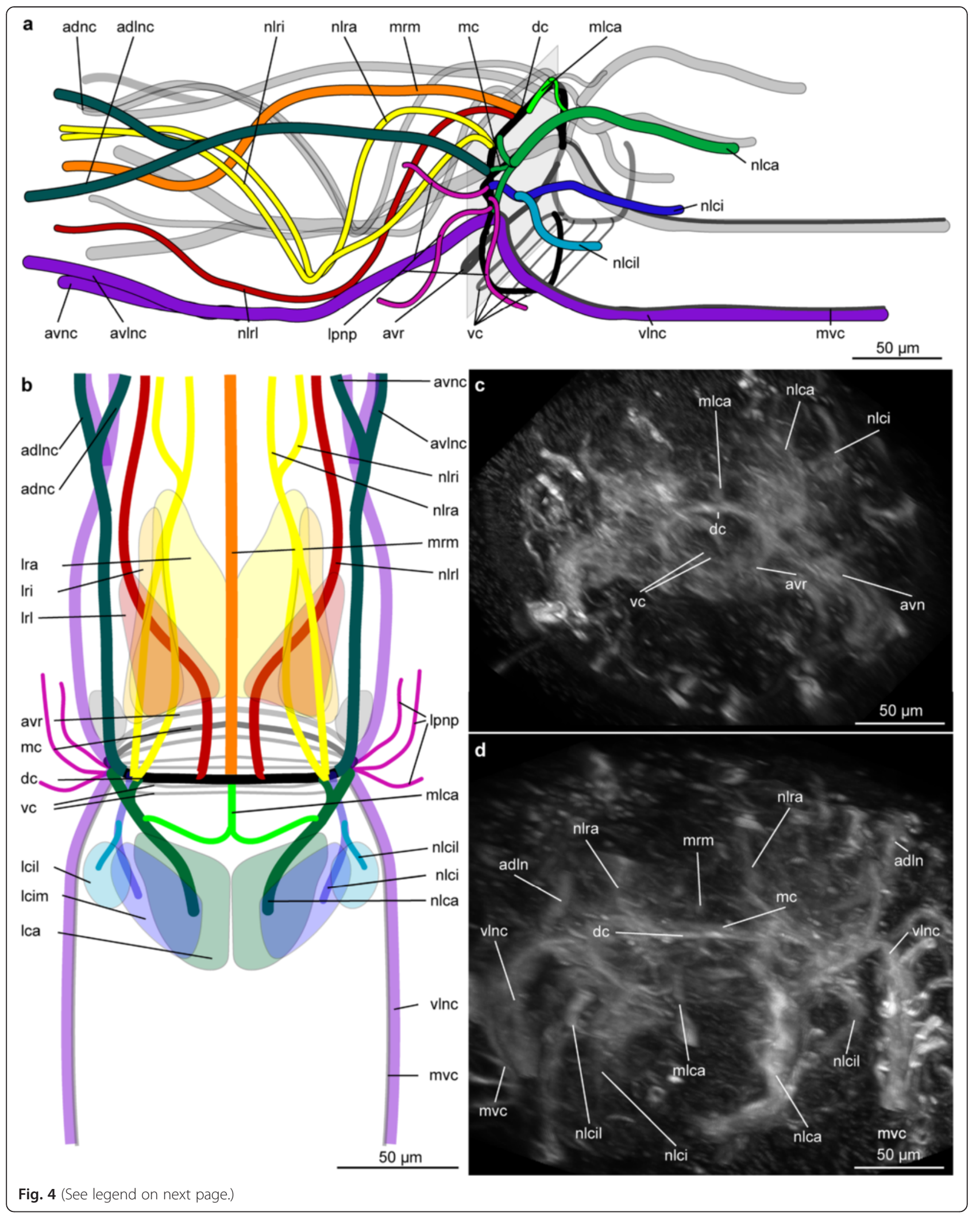


(See figure on previous page.)

Fig. 4 Details of the nerves of the brain of Lobatocerebrum riegeri n. sp. as seen with CLSM, acetylated a-tubulin in grey. a, b Schematic drawings based on confocal stacks, $\mathbf{c}, \mathbf{d}$ maximum intensity projections of the original image stack. a Brain in dorsolateral view, with the major nerves of the left side colour-coded, the nerves of the right side shaded in grey $\mathbf{b}$ Dorsal view of the brain with similar colour-coding and indication of the nerves, $\mathbf{c}$ dorsal view of the central neuropil at the level of the main commissures in the brain; $\mathbf{d}$ dorsal view of the central neuropil with the major nerve cords as shown in the schematic drawings. Abbreviations: adlnc: anterior dorsolateral nerve cord, adnc: anterior dorsal nerve cord, avc: anterio-ventral commissure of the neuropil, avlnc: anterior ventrolateral nerve cord, avnc: anterior ventral nerve cord, dc: dorsal commissure of the neuropil, Ica: major caudal lobe, Icil: lateral minor caudal lobe, Icim: median minor caudal lobe, Ipnp: lateral projection of the neuropil, Irl: lateral rostral lobe, Ira: major rostral lobe, Iri: minor rostral lobe, mc: median commissure of the neuropil, mlca: medial nerve innervating the major caudal lobe, mrm: median rostral nerve, nlca: nerve innervating the major caudal lobe, nlci: nerve innervating the median minor caudal lobe, nlcil: nerve innervating the lateral minor caudal lobe, nlrl: nerve leading through the lateral rostral lobe, nlra: nerve leading through the major rostral lobe, nlri: nerve leading through the minor rostral lobe, mvc: medioventral nerve cord, vinc: ventral nerve cord, vc: ventral commissure of the neuropil

These nerves are thinner than the ones of the central nervous system $(0.5 \mu \mathrm{m}$ in diameter) and consist of only very few to individual nerve fibres. The longitudinal peripheral nerves (lpn, Figs. 5h-i) trace the longitudinal muscle bundles throughout the body ( $\mathrm{lm}$, Fig. $5 \mathrm{i})$. In the most posterior part of the body, though, they could not be detected with acetylated $\alpha$-tubulin IR due to the overlaying signal of the central nervous system and the various glands. Their specific origin cannot be assessed, though these thin nerves seem to descend from the central neuropil rather than from the ventrolateral nerve cords.

The incomplete circular nerves (tpn, Fig. 5h) are closely associated with the commissures in the ventral nerve cord, at the level of which they extend from the ventrolateral nerve cords to the dorsal side of the animal. Here, they connect to the longitudinal peripheral nerves exterior to the longitudinal muscle bundles and create a circular connection among these. Additionally and independent of the commissures, one transverse nerve anterior to the pharynx forms an incomplete circle including only lateral and dorsal peripheral longitudinal nerves and three closed rings include all longitudinal peripheral nerves at the level of the seminal receptacles. The latter are set 30-35 $\mu \mathrm{m}$ apart (Fig. 1a). Some additional circular peripheral nerve rings are also found scattered throughout the body. However, they could not be related to any specific structures or reveal a consistent pattern in all specimens investigated.

\section{Tyrosinated tubulin-IR}

Immunoreactivity of the tyrosinated tubulin-antibody did not reveal any additional structures adding to the pattern already seen with acetylated $\alpha$-tubulin-IR. On the contrary, the commissure inside the brain as well as the peripheral nerves could not be revealed using this antibody.

\section{Serotonin-IR}

Serotonin-IR was not only labeling nervous structures, but also glands (uni- and multicellular) and stomach content, where the antibodies most likely got retained between particles or in vesicles (Fig. 5e). However, strong labeling of some but not all epidermal cells could be found, with the IR being located in the entire cytosol, but not in the nucleus, which made them therefore resemble serotonergic perikarya (spc, Fig. 5e). Since there was no connection to the nervous system, they could also be specialized gland or epidermal cells with so-far unknown function.

Serotonin-IR also labels all three longitudinal nerves of the ventral nervous system, with one or two strands inside the thick bundles. This pattern is also present in all commissures, but serotonin-IR cannot be detected in any of the peripheral nerves. In the ganglionic pairs associated with the two pharyngeal commissures, four to five perikarya show serotonin-IR, but do not display any specific arrangement inside the ganglion: They seem to be randomly spread between the other cells (spg1-2, Fig. 5e). Additional perikarya with serotonin-IR are found scarcely along the ventral nerve cord.

\section{FMRFamide-like-IR}

FMRFamide-like-IR was not consistent between the two specimens investigated. This is mainly due to the rostral glandular structures, which seem to be lying adjacent to the nervous system in Lobatocerebrum, and to differences between the studied individuals. Similar to the serotonin - IR described above, the three ventral nerves of the central nervous system, the posterior projection from the terminal commissure (pp, Fig. 5c), as well as the commissures of the central nervous system are revealed using FMRFamide-like-IR (Figs. 3c and 5a). Interestingly, while several nerve fibres in the lateral nerve cords seem to be FMRFamidergic, only one single fibre in the median nerve cord shows this IR, most likely emerging at the level of the pharyngeal commissures. There are no FMRFamidergic perikarya along the ventral nervous system. Only one FMRFamidergic perikaryon in each of the two subpharyngeal ganglia was detected seemingly contributing to the pharyngeal commissure (fpg1-2, Fig. 5a), though its location does not seem to be truly consistent between all specimens investigated. 


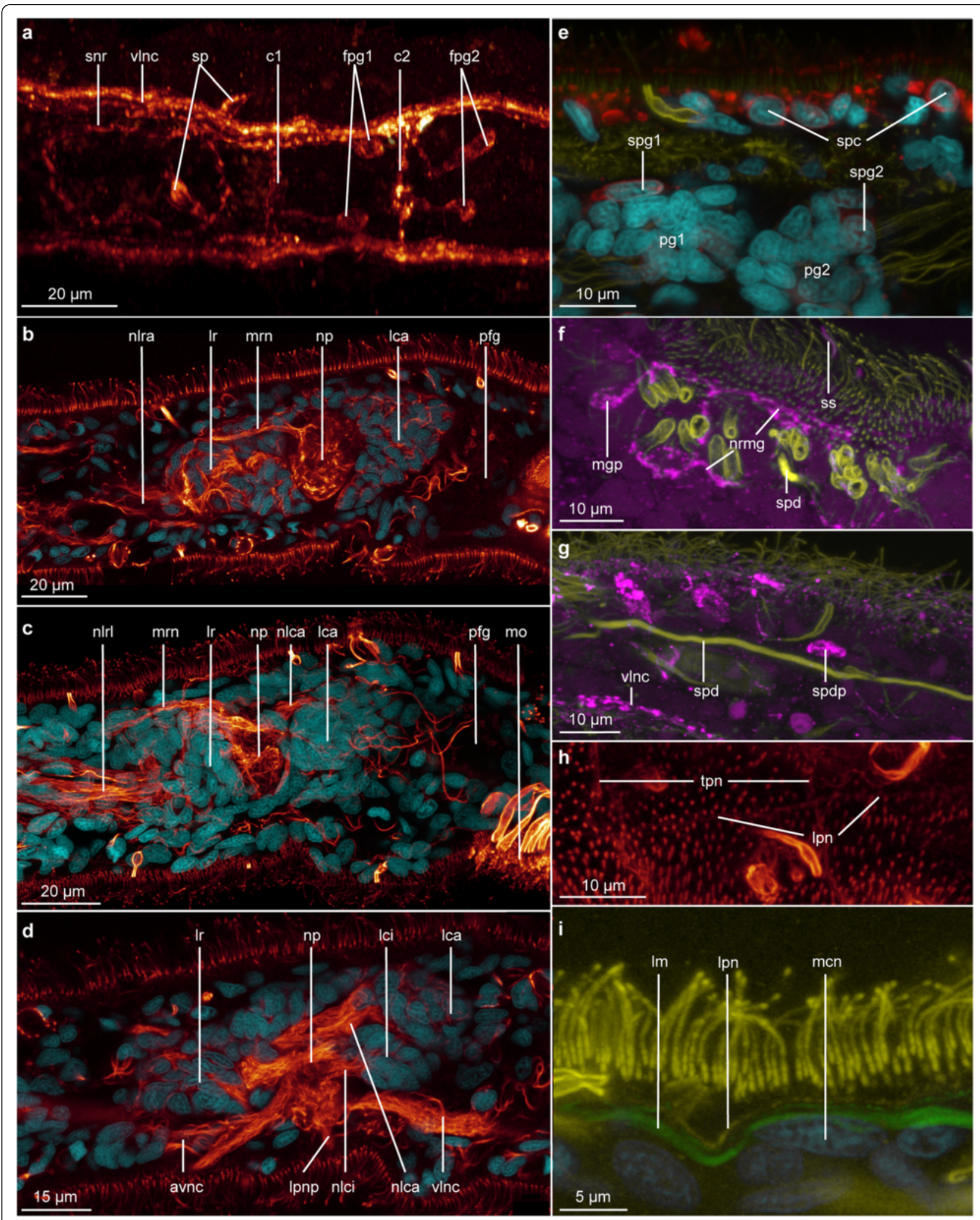

Fig. 5 (See legend on next page.) 
(See figure on previous page.)

Fig. 5 Details of the nervous system of Lobatocerebrum riegeri $\mathrm{n}$. sp. as seen with CLSM. DAPI in cyan, serotonin in red, FMRFamide in purple. The use of "glow" depends on the figure and is indicated for each of them. All images are maximum intensity projections of a subset of the original image stack on various locations of the body if not specified below. Anterior is to the left and posterior to the right a Dorsal view of the details of the FMRFamidergic nervous system around the pharynx in "glow". The background noise has been masked to highlight the nervous system. $\mathbf{b}, \mathbf{c}$ and $\mathbf{d}$ Single sagittal sections showing details of the brain. a-tubulin in "glow", b-d Virtual sections through the median plane (b) the medio-lateral plane (c) and the lateral plane (d) of the brain, e Coronal substack of the animal showing details of the epidermis and the postpharyngeal ganglia (the outside of the animal is on the upper side of the picture), $\mathbf{f}$ Dorsal view of a sub-stack of the male gonopore (the outside of the animal is on the upper side of the picture), $\mathbf{g}$ Dorsal view of a sub-stack of the spermioduct, $\mathbf{h}$ Dorsal view of a sub-stack of epidermis showing the peripheral nervous system with a-tubulin in glow, $\mathbf{i}$ Sub-stack showing a longitudinal section of the epidermis with details on the peripheral nervous system associated to the musculature (the outside of the animal is on the upper side of the picture). Abbreviations: avnc: anterior ventrolateral nerve cord, c1-2: commissure 1 - 2, fpg1-2: FMRFamidergic perikarya of the postpharyngeal ganglia 1 - 2, Ica: major caudal lobe, Ici: minor caudal lobes, Im: longitudinal muscle, Ipn: longitudinal peripheral nerve, Ipnp: lateral projection of the neuropil, Ir: rostral lobe, mcn: nuclei of the myocyte, mo: mouth opening, mop: perikaryon associated with the male gonopore, mrn: median rostral nerve, nlca: nerve of the major caudal lobe, nlci: nerve of the minor caudal lobe, nlra: nerve of the major rostral lobe, nlrl: nerve of the lateral rostral lobe, np: neuropil, nrmg: nerve ring around the male gonopore, pfg: posterior frontal glands, pg1-2: postpharyngeal ganglia 1 - 2, snr: stomatogastric nerve ring, sp: perikarya of the stomatogastric nerve ring, spc: serotoninergic cell, spd: spermioduct, spdp: FMRFamidergic perikarya associated to the spermioduct, spg1: serotoninergic perikarya of the postpharyngeal ganglion 1, ss: sensoria, tpn: transverse ring of the peripheral nervous system, vinc: ventral longitudinal nerve cord

Possibly as part of the stomatogastric nervous system, two additional pairs of perikarya were revealed dorsal to the mouth and lateral to the pharynx, respectively. Since they are connected ventrally via a thin nerve strand, they seem to constitute the stomatogastric nerve ring described by Rieger ([8], snr, Fig. 5a). Surrounding this structure and disguised by the strong IR of the pharyngeal glands, additional perikarya with very weak FMRFamide-like-IR (sp, Fig. 5a) are found. A further differentiation between the perikarya of the stomatogastric nerve ring and the immune-reactive glands is not possible with any antibody employed in this study.

Though no evidence of the peripheral nervous system could be detected with FMRFamide-like - IR, a FMRFamidergic nerve net is found around the male gonopore. It consists of a thin nerve ring around the male gonopore (nrmg, Fig. 5f) and several individual neurites projecting radially into the ring from their perikarya (mgp, Fig. 5f). Though they are found in all specimens, their number and distribution pattern vary strongly. Additionally, four FMRFamidergic perikarya are distributed scarcely along the spermioduct (spdp, Fig. 5f). No nervous system could be found associated with the ovary or the seminal receptacles.

\section{Glandular structures}

Studied in LM, with acetylated $\alpha$-tubulin and DAPI staining in CLSM, and in TEM, Figs. 6, 7. Acetylated $\alpha$-tubulin-IR of the glandular cell walls [37] proved useful to identify and describe several types of glandular cells in the epidermis.

\section{Epidermal glands}

Four types of unicellular epidermal glands were distinguished by acetylated $\alpha$-tubulin-IR and CLSM: a) ciliated glands; b) smooth flask-shaped glands; c) kidney-shaped gland; and d) unicellular adhesive glands.

Ciliated glands The ciliated gland cells (cg, Figs. 6a-c, 7b ) are the largest of the unicellular epidermal glands (diameter 6.9-8.1 $\mu \mathrm{m}$, length 9.3-11.2 $\mu \mathrm{m}, n=3, r=$ $1-4, m=5)$, distally with a ring formed by shortened stiff cilia around their external opening (sc, diameter $0.6-1.5 \mu \mathrm{m}, n=3, r=1-4, m=5$, Fig. $6 \mathrm{a}, \mathrm{b})$ and proximally extending into a 30-50 $\mu \mathrm{m}$ long $(n=3, r=1-4$, $m=5$ ), thin tail-region lining the basal membrane. The broad distal region of the gland cells containing the nucleus is located intraepidermally, occasionally alongside the longitudinal muscle bundles, since these are sunken into the epidermal layer (Fig. 6a). The gland cell membranes are lined by twelve to twenty pairwise arranged tubulinergic filaments (tst, $n=3$, $r=1-4, m=5)$. The cell nucleus has approximately the same size and heterochromatin-content as the nuclei of the surrounding epidermal cells (Fig. 6a-b). The gland cells are packed with non-electron-dense to weakly-electron-dense vesicles (gv, Fig. 6c). They are found scattered throughout the entire body, though they are most abundant in the posterior region, mainly from the midgut-hindgut-transition towards the posterior end of the body. Although the cellular tail region of the cell may tangent a nerve cord, no close connection or direct nervous innervation of the glands, nor indications of muscular control, were found with CLSM or TEM.

These cells most likely resemble the 'mucous gland type 1 ' in $L$. psammicola described by Rieger $[8,10]$, having a similar characteristic ring of shortened cilia around the opening. This is further corroborated by the similar shape and electron density of the vesicles of these glandular cells $[8,10,11]$. 
a
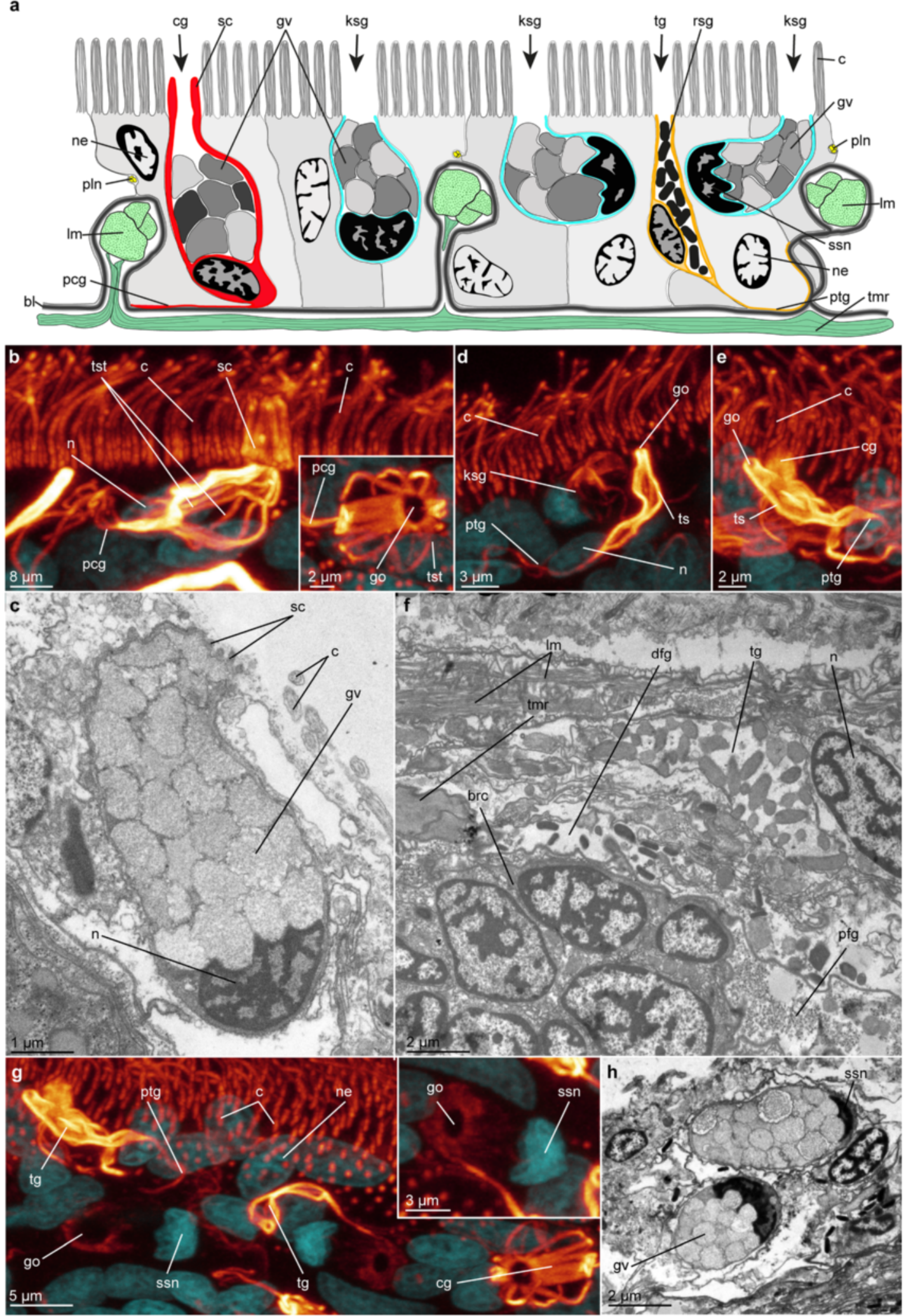

Fig. 6 (See legend on next page.) 
(See figure on previous page.)

Fig. 6 Epidermal glands in Lobatocerebrum riegeri n. sp. as seen with CLSM and TEM. DAPI in cyan, acetylated a-tubulin in glow. b, $\mathbf{d}-\mathbf{e}$, $\mathbf{g}$ are maximum intensity projections of a subset of the original image stack on various locations of the body, $\mathbf{c}, \mathbf{f}$, $\mathbf{h}$ ultrastructural details of the epidermis. a Schematic cross section drawing of the epidermis with all three glandular cell types in their approximate abundance, $\mathbf{b}$ ciliated gland cell with closed circle of shortened cilia (inset with details of the tubular strands in the cellular membrane), c Sagittal section of a ciliated gland cell, $\mathbf{d}$ Tubular gland cell in the epidermis, e Tubular gland cell with long projection in the epidermis, $\mathbf{f}$ Sagittal section through the epidermis of the rostrum, presenting a tubular epidermal gland adjacent to a duct of the posterior frontal gland and the brain, $\mathbf{g}$ Kidney-shaped glands in the epidermis (inset with details of the glandular opening), $\mathbf{h}$ Cross section through a kidney-shaped gland. Abbreviations: afg; anterior frontal gland; bl: basal lamina, brc: brain cell, c: cilium, cg: ciliated gland cell, dfg: duct of the frontal gland, go: glandular opening, gv: glandular vesicle, ksg: kidney-shaped gland cell, Im: longitudinal muscle, n: nucleus, ne: nucleus of epidermal cell, pcg: projection of the ciliated gland cell, pfg: posterior frontal gland, pln: peripheral longitudinal nerve, ptg: projection of the tubular gland cell, rsg: rod-shaped granule, sc: shortened cilium, ssn: sickle-shaped nucleus, tg: tubular gland cell, tmr: transverse muscular ring complex, ts: tubulinergic sheath, tst: tubulinergic strand

Tubular glands Tubular gland cells (tg) do not have a ciliary ring around their opening, but a continuous lining of acetylated $\alpha$-tubulin IR in the membrane lining the cell (diameter 1.5-3.2 $\mu \mathrm{m}$, length 7.8-8.9 $\mu \mathrm{m}, n=3, r=1-4$, $m=5$, Fig. $6 \mathrm{~d}, \mathrm{e})$. They are generally characterized by a slender distal neck-area before the cell widens proximally (Fig. 6a, d, e). However, a few cells with wide distal openings have been found. A long, thin tail extends from the basal part of the cell up to $30 \mu \mathrm{m}$ along the basal lamina, apparently without connecting to any other structure (Fig. 6a). In contrast to the ciliated glands, the smaller sized tubular gland cells mainly occupy the more distal part of the epidermal layer, distal to the muscle bundles (Fig. 6a). These gland cells are filled with electron-dense, rod-shaped granules $(0.8-1.5 \mu \mathrm{m}$ in length, $0.2-0.5 \mu \mathrm{m}$ in width, $n=3, r=1-4, m=5$ ), which are less densely packed than the vesicles of the adhesive glands (Fig. 6e). They are highly abundant throughout the entire body (10-15 cells per $100 \mu \mathrm{m}$ body length, $n=3, r=1-4, m=5$ ), with the densest distribution in the posterior region of the body.

Kidney-shaped glands Only one glandular cell type (kidney-shaped gland cell, ksg) can be distinguished by the shape of its nucleus: In contrast to all other epidermal cell nuclei, nuclei of kidney shaped gland cells are strictly sickle-shaped (Fig. 6a, g, h) and their chromatin denser than the also "deformed" nuclei of ciliated glands (Fig. 6c). The cell membrane only contains very few tubulinergic elements; yet, dense acetylated $\alpha$-tubulinergic-IR can be detected around the cell opening (diameter 1.1$1.7 \mu \mathrm{m}, n=3, r=1-4, m=5)$ and at its base. The overall appearance of the cell is characteristically kidney-shaped (diameter 3.3-4.7 $\mu \mathrm{m}$, length 6.9-7.8 $\mu \mathrm{m}, n=3, r=4, m=$ 5, Fig. 6e). Kidney-shaped gland cells are mainly found in the distal part of the epidermal layer similar to the tubular gland cells (Fig. 6a). However, the basalmost part of the cell, which contains the nucleus, can also be found close to or even internal to the longitudinal muscle bundles (Fig. 6a, g). These glandular cells are most likely imparting the greenish speckled appearance of the animals in live observations (Additional file 1) due to the refractive index of their content, which consists of non- to weakly-electron dense and tightly packed vesicles (diameter 0.6-1.2, $n=3$, $r=1-4, m=5$, Fig. $6 \mathrm{~h}$ ). In contrast to the ciliated gland cells, the vesicles of the kidney-shaped gland cells are less homogenous in the electron-density of their content, and denser in their packing, possibly causing the sickle-shape of the nucleus.

Unicellular adhesive glands The unicellular adhesive glands are characterized by a ring of shortened cilia around the opening, which was suggested to facilitate mechanical loosening from the substrate instead of a second enzymatic gland with releasing function $[8,10]$ and therefore morphologically resembles the ciliated glands though their content and function differ (Fig. 7a, b). Their secretion is granular, but shows a characteristic structure with an inner, electron-dense area in a non-electron-dense oval structure (Fig. 7a, b). Different to the adhesive glands described in L. psammicola, the glands of L. riegeri $\mathrm{n}$. sp. do not have linear electron-dense structures in the middle of the individual granules, but instead linearly arranged electron-dense dots (Fig. 7a, b). Contrary to the abundance and distribution pattern of the other epidermal glands cells mentioned above, adhesive gland cells are restricted to the ventral surface of the body in lower numbers (1-5 cells per $100 \mu \mathrm{m}$ ventral body length, $n=3$, $r=1-4, m=5)$.

\section{Frontal glands}

The main body of the paired posterior frontal glands (pfg) is found posterior to the brain and anterior to the pharyngeal region (Figs. 5b, c , 7c). This part of the glands is difficult to detect with any of the antibodies described above, but can be found combining the lack of DAPI-signal with overexposed phalloidinsignal to detect cell membranes and nuclei of voluminous cells in a large lobular structure posterior to the brain lobes (Fig. 7c). The glandular nuclei are slightly larger than the ones of the brain (diameter 4.3$5.7 \mu \mathrm{m} \times 1.4-2.5 \mu \mathrm{m}, n=3, r=1, m=5)$. While the gland body itself is inconspicuous in CLSM, its long ducts, which are leading ventroanterior of the brain to the tip of the rostrum, are showing distinct acetylated $\alpha$-tubulin-IR 

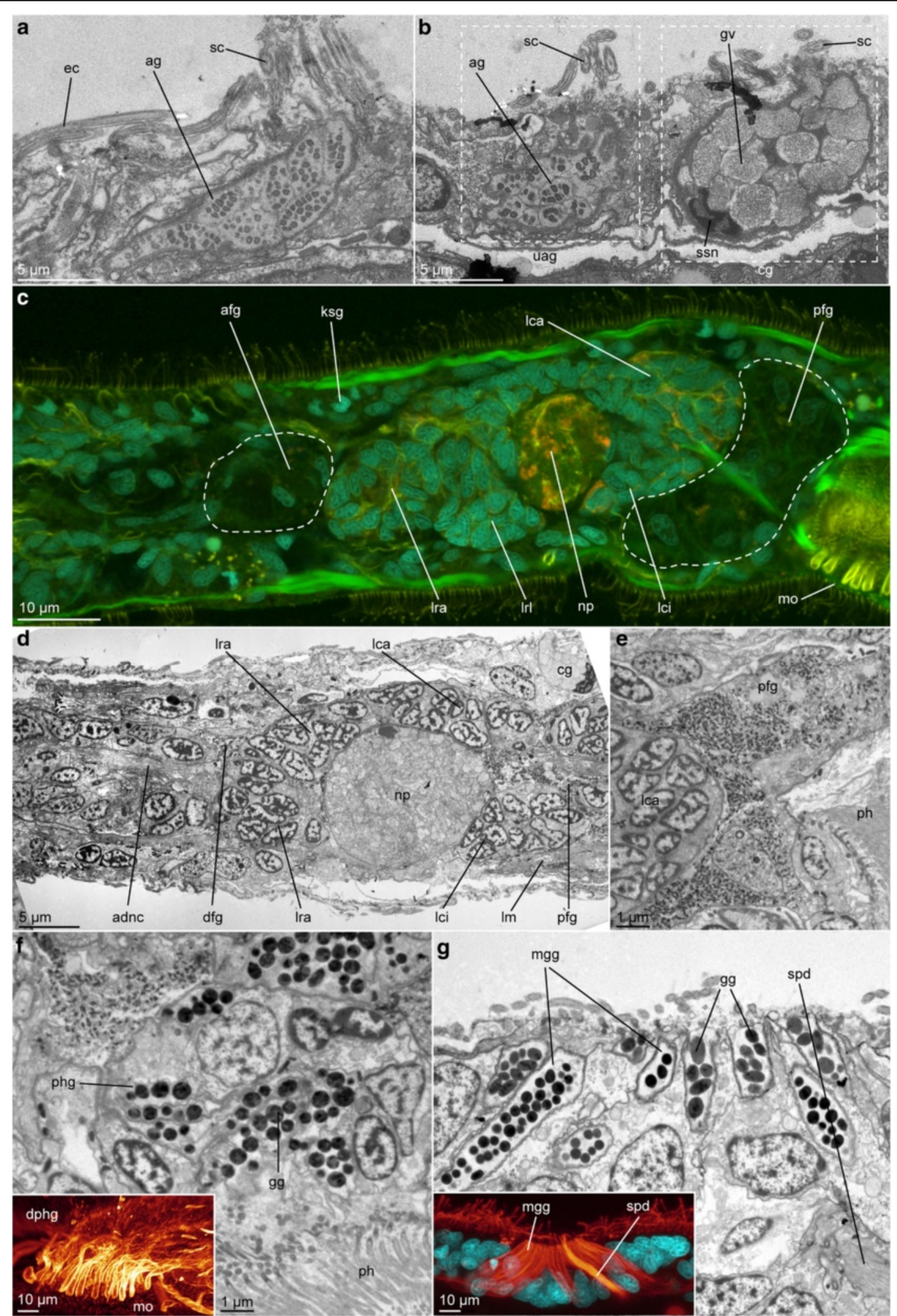

Fig. 7 (See legend on next page.) 
(See figure on previous page.)

Fig. 7 Specific glandular systems in Lobatocerebrum riegeri n. sp. as seen with CLSM and TEM. DAPI in cyan, acetylated a-tubulin in glow or yellow, actin-filaments in green. $\mathbf{c}, \mathbf{g}, \mathbf{h}$ are maximum intensity projections of a subset of the original image stack on various locations of the body, $\mathbf{a}$, $\mathbf{b}$, $\mathbf{d}-\mathbf{f}$ ultrastructural details of glandular structures. a Sagittal section through the epidermis and an unicellular adhesive gland, $\mathbf{b}$ Sagittal section through an unicellular adhesive and a ciliated gland in the epidermis, $\mathbf{c}$ brain and portions of the anterior and posterior frontal glands (indicated by white dashed line), d Sagittal section through the anterior tip of the rostrum with ducts of the posterior frontal glands and nerves, e Sagittal section through the mouth opening with glandular cells of the posterior frontal gland and the pharyngeal gland, $\mathbf{f}$ Sagittal section through the pharyngeal region with distal parts of the pharyngeal glands, $\mathbf{g}$ Distal regions of the ducts of the pharyngeal glands, $\mathbf{h}$ Glands around the male gonopore. Abbreviations: afg: anterior frontal gland, ag: adhesive granule, cg: ciliated gland cell, dfg: ducts of the frontal gland, dphg: ducts of the pharyngeal gland, ec: cilia of an epidermis-cell, gg: glandular granules, gv: glandular vesicle, ksg: kidney-shaped gland, Ica: major caudal lobe, Ici: minor caudal lobe, Irl: lateral rostral lobe, Ira: major rostral lobe, mo: mouth opening, mg: male gonopore, mgg: male gonopore gland, np: neuropil, pfg: posterior frontal gland, sc: shortened cilium, spd: spermioduct, ssn: sickle-shaped nucleus, uag: adhesive gland cell

(Fig. 3a-c, e, 7d). Posteriorly the ducts are straight and grouped into two bundles; anteriorly they ramify into a fan of duct openings framing the anterior edge (Figs. 1a, 3b, c, e). Ramifying longitudinal nerves are found accompanying these in the rostrum but possible nervous innervation of the frontal glands could not be resolved. The cellular content of the posterior frontal glands consist of very small (diameter $0,2-0,3 \mu \mathrm{m}, n=1, r=1, m=10$ ) spherical, electron-dense granules, which seem to increase in diameter towards the anterior tip of the animal and the opening of the duct (Fig. 7d, e). This glandular content can clearly be distinguished by their shape from the content of the epidermal cells described above (big vesicles) and the granules of the anterior frontal glands (rod-shaped granules, Figs. 6a, c, f, h, 7a, b, d-f).

An additional, smaller pair of frontal glands, located anterior to the brain, has been reported by Rieger [10], and is possibly also present in Lobatocerebrum riegeri $\mathrm{n}$. sp. (Fig. 7c). As for the posterior frontal glands, their presence could be detected indirectly with CLSM by paired, seemingly empty cavities filled by large cells with elongated nuclei and distinctly tubulinergic ducts. Some of these short ducts opening midventrally did show acetylated alpha-tubulin-IR. However, not all ducts could be traced with certainty to their external ventral openings, since they do not seem to possess the same high density of tubulinergic elements as the ducts of the posterior frontal glands. In the same ventral location of the rostral tip of the animal, TEM showed several tubelike structures with more electron-dense and narrow granules than detected in the tubular glands (Fig. 6f), which are assumed to constitute the secretion of the anterior frontal glands (afg, Fig. 7d).

\section{Pharyngeal glands}

The major glandular structures of the digestive system are the big, multicellular glands of the pharynx, whose products are secreted in the area of the mouth opening (Fig. 7e). 17-18 elongated ducts (diameter 1.8-3.5 $\mu \mathrm{m}$, length 70-100 $\mu \mathrm{m}, n=3, r=2, m=5$, Fig. $7 \mathrm{~g}$ ) of posteriorly located glands surround the mouth opening. They are arranged in a denser pattern in its posterior third, while they are more loosely set anteriorly. The main glandular body can be detected posterior to the mouth opening, on the ventral side of the body dorsal to the ventral nerve cords. It is seen as an elongated, baglike structure filled with spherical, electron dense granules (1.2-1.7 $\mu \mathrm{m} . n=2, r=2, m=5)$ best detected with FMRFamide-like-IR or TEM (Fig. 7e-g). These glands are not epidermal, and their cell bodies are found inside both the longitudinal musculature and transverse muscular ring complexes of the body wall.

\section{Male gonopore glands}

Acetylated tubulin-IR was recovered in cells surrounding the dorsal male gonopore. The openings of 16-20 $(n=3$, $r=2-3, \quad m=5)$ gland cells constituting the complex (Fig. 7h) are connected to the gland bodies via elongated, thin ducts, which are $1.0-1.5 \mu \mathrm{m}$ in diameter and are all leading to a sunken-in area (14.8-18.3 $\mu \mathrm{m} \times 6.4-8.2 \mu \mathrm{m}$, $n=3, r=2-3, m=5$, Fig. $7 \mathrm{~h}$ ) around the male gonopore. Approximately half of the cells are densely packed around the anterior end, and the other half around the posterior end, with a small gap between the two portions.

\section{Reproductive system}

Studied in LM, with acetylated $\alpha$-tubulin and DAPI staining in CLSM, Fig. 8.

In all four adult animals investigated, both male and female reproductive organs or gametes could be found, as well as seminal receptacles to store the mating partner's sperm.

\section{Male gonad}

The male gonad is located on the dorsolateral side of the animal, posterior to the third commissure. It is an elongated, thin structure, with the gonopore opening on the dorsal surface of the animal (diameter 1.5-2.7 $\mu \mathrm{m}, n=3$, $r=2-3, m=3$, Figs. $7 g, 8 \mathrm{a}$ ). A thin channel (diameter 1.4-1.8 $\mu \mathrm{m}, n=3, r=2, \mathrm{~m}=5$ ) extends posterior to the pore, with a high amount of the long, thin, fibrous sperm stored in the posterior region (Fig. 8a). Where the sperm is produced is unclear; however, the majority of 

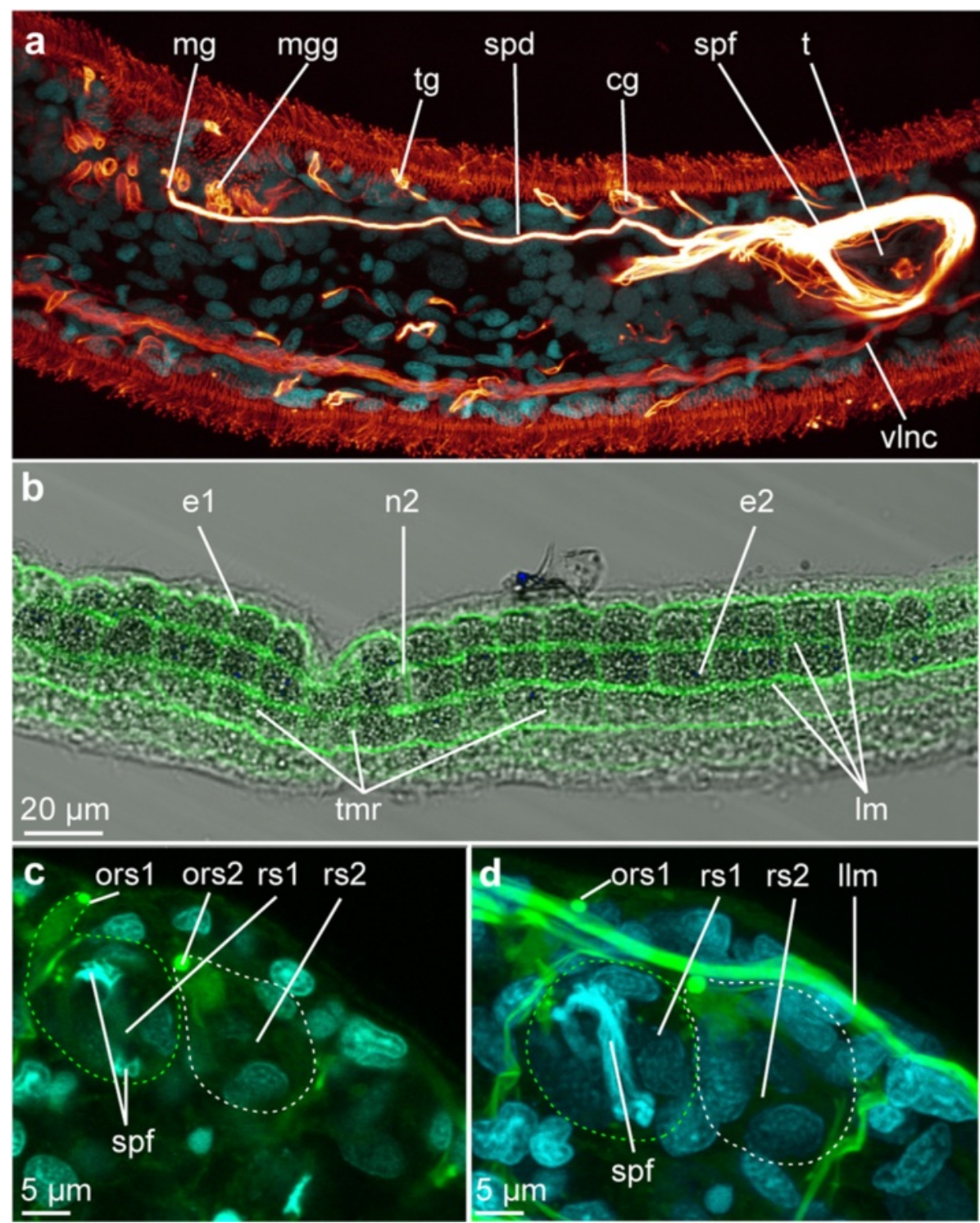

Fig. 8 Reproductive organs in Lobatocerebrum riegeri n. sp. as seen with CLSM and transmitted light. DAPI in cyan, acetylated a-tubulin in glow, phalloidin in green. All images are maximum intensity projections of a subset of the original image stack. Orientation is anterior to the left and dorsal side up if not indicated otherwise. a Testis with spermioduct and glands around the male gonopore, $\mathbf{b}$ Ovary, $\mathbf{c}-\mathbf{d}$ Seminal receptacles at the level of the tips of the sperm filaments $\mathbf{c}$ ) and with bent sperm filaments $(\mathbf{d})$. The contours of the receptacles are traced with dashed lines to facilitate orientation. Abbreviations: cg: ciliated gland, e1-2: egg 1 - 2, Ilm: lateral longitudinal muscle, Im: longitudinal muscle, mg: male gonopore, mgg: male gonopore glands, n2: nucleus of egg 2, ors1-2: opening of the seminal receptacle 1-2, rs1-2: seminal recepatcle 1-2, spd: spermioduct, spf: sperm filaments, t: testis, tg: tubular gland, tmr: transverse muscular ring complex, vlnc: ventral longitudinal nerve cord

glands involved in this apparatus are arranged around the gonopore itself, as described above, creating a glandular field (16.2-17.0 $\mu \mathrm{m} \times 3.5-5.4 \mu \mathrm{m}, n=3, r=2,3$, $m=4$, Figs. 7a, b, 8a).

\section{Female gonad}

Up to four eggs, lined up behind each other and increasing in volume posteriorly (Fig. 8b), are the only structures of the female gonad detected with either immunohistochemistry or live observations. The eggs are of irregular shape, reflecting the available space in the body. Although the openings of both seminal receptacles and the male gonad have been found, no obvious opening was detected near the eggs, and they may have to be deposited via rupturing of the epidermis.

\section{Seminal receptacles}

In the posterior part of the body, the adult animals form one to several seminal receptacles (rs, Fig. 8c, d). These receptacles are thin-walled capsules consisting of few 


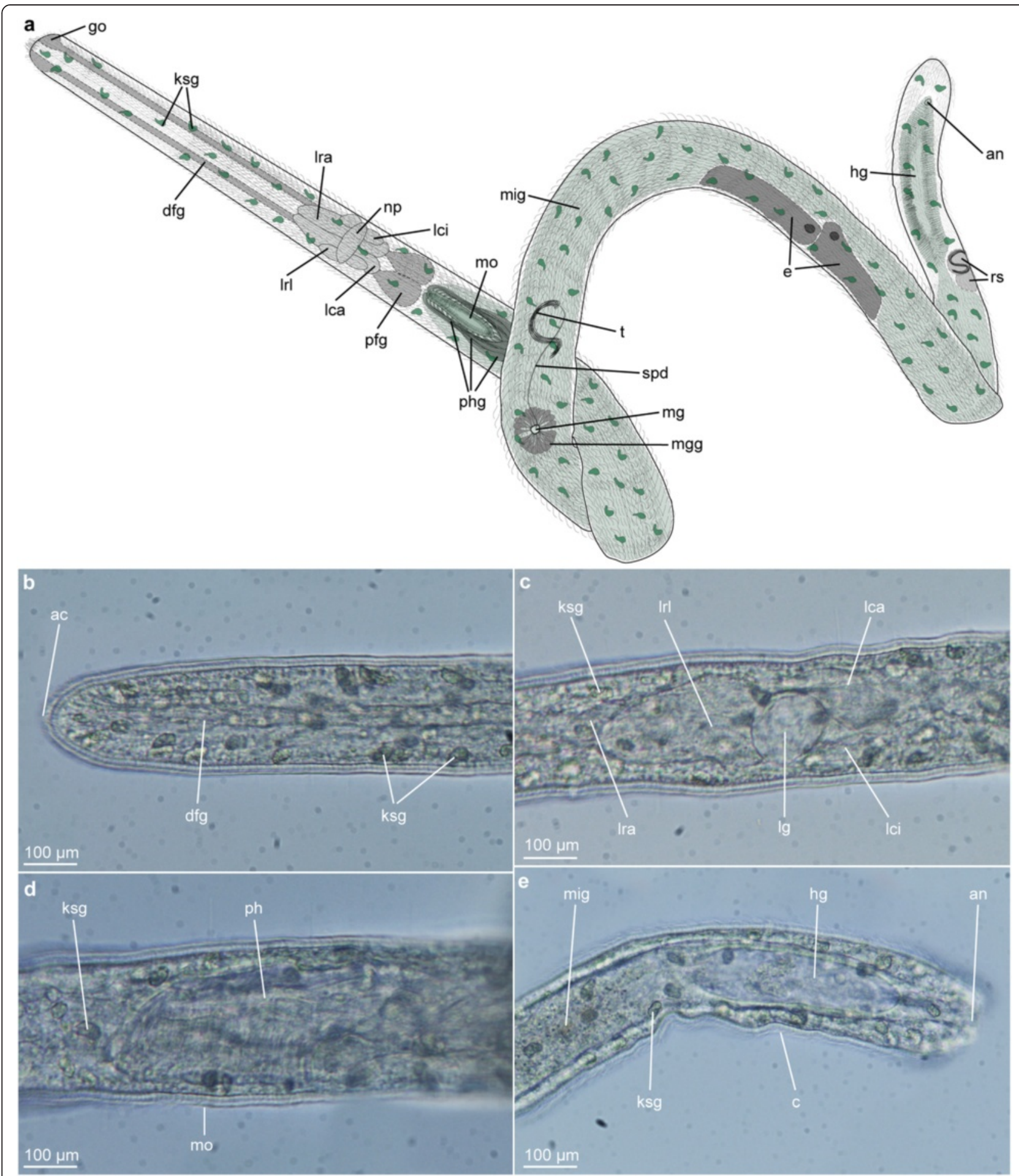

Fig. 9 Lobatocerebrum riegeri n. sp. Anterior is to the left and dorsal to the upper side of the picture in the light micrographs (b-e). a Partly schematized drawing of an adult Lobatocerebrum riegeri $\mathrm{n}$. sp. with the most significant traits emphasized based on light microscopic observation. b anterior part of the rostrum with glandular epidermis and frontal gland ducts, $\mathbf{c}$ brain, $\mathbf{d}$, ciliated pharynx and e posterior end of the body with midgut-hindgut-transition in lateral view. Abbreviations: ac: anterior cilia, an: anus, c: cilium, dfg: frontal gland ducts, hg: hindgut, go: glandular opening, ksg: kidney-shaped gland, Ica: major caudal lobe, Ici: minor caudal lobe, Ig: lateral ganglion, Ira: major rostral lobe, Irl: lateral rostral lobe, mg: male gonopore, mgg: male gonopore gland, mig: midgut, mo: mouth opening, np: neuropil, ph: pharynx, phg: pharyngeal gland, rs: seminal receptacles, spd: spermiduct, t: testis 
cells without any specific immunoreactivity (Fig. 8c, d). Their diameter is $20-30 \mu \mathrm{m}(n=3, r=1, m=4)$, and the sperm filaments (spf) can be seen inside, bent and curled up (Fig. 7e). The openings of the receptacles (ors, diameter $0.8-1.7 \mu \mathrm{m}, n=3, m=3)$ are on the ventrolateral side of the body (Fig. $8 \mathrm{c}$ ).

\section{Motility patterns}

Studied in LM, Additional file 1.

\section{Ciliary locomotion}

Lobatocerebrum riegeri $\mathrm{n}$. sp. is uniformly ciliated along the entire body and moves mainly by a relatively slow, but steady back and forward ciliary gliding rather than muscular action (Additional file 1). Ciliary mode of locomotion is cost-efficient for minute interstitial animals, yet fast reactions to avoid obstacles are dealt with by contractions of the longitudinal (and to a lesser degree transverse musculature ring complexes) body wall muscles.

\section{Muscular locomotion}

Behavioral observations of several specimens revealed different movement patterns of the rostrum and the remaining body: while the posterior part of the body was often found curled up and attached to the substrate, the anterior part did exploratory movements, including contraction along the longitudinal body axis and sweeping of the rostrum from side to side (Additional file 1). This coincides with the lack of transverse muscular ring complexes and presence of star-shaped muscles in the rostrum. During these contractions of the longitudinal muscles, the anterior part of the body appears more wrinkled, also indicating that an elongation or contraction of the longitudinal muscles in the anterior region is not affecting the trunk and posterior part of the body. With all the longitudinal muscles being continuous along the entire body, the stabilizing and immobilizing of the median body during longitudinal contractions may be accomplished by counteracting contractions of the transverse muscular ring complexes in the trunk and posterior part of the body.

The animals also regularly curl up or fold their posterior body in sinuous curves, which may facilitate anchoring the body among sand grains in the substrate. The trunk may also show minor contractions and winding movements occasionally providing a forward movement in a snake-like pattern (Additional file 1). This most likely is due to a combination of muscular and ciliary locomotion.

The posteriormost end of the body can also be active and flexible (performing contractions and elongations as well as bending movements), though this motility is limited to a small region anterior to the anus $(10-30 \mu \mathrm{m}$, $n=3, r=4, m=5)$. Occasionally, when the posterior part is curled up or bent, it would act more as an anchor rather than promote forward movement (Additional file 1). Lobatocerebrum riegeri $\mathrm{n}$. $\mathrm{sp}$. has never been observed to leave the substrate and swim into the water column.

\section{Movements in the digestive system}

Although no feeding behavior could be observed, stomach content was moved continuously in both directions, even when the animal was not moving (Additional file 1). This indicates that the weak musculature of the digestive system, maybe together with the body wall musculature, is responsible for movement of the food through the body. The fifth sphincter here probably plays an important role in sealing the digestive tract and prohibiting food getting expelled through the pharynx and mouth opening again, since no movement of food could be observed in the pharynx anterior to this muscular constriction.

\section{Taxonomy}

Phylum Annelida Lamarck, 1809

Family Lobatocerebridae Rieger, 1980

Genus Lobatocerebrum Rieger, 1980

Species Lobatocerebrum riegeri $\mathrm{n}$. sp.

(Figs. 1, 2, 3, 4, 5, 6, 7, 8, 9, Tables 1, 2, 3, 4, Additional file 1)

Lobatocerebrum sp. 2 in [8-11], registered in ZooBank (E3DCE97A-7F7A-4799-827A-DF2EA41AE1A5).

\section{Diagnosis}

Entirely ciliated Lobatocerebrum, unsegmented, hyaline body with glandular epidermis (unicellular, kidney-shaped glands with transparent-green content), 1.08-1.6 $\mathrm{mm}$ in length and 0.04-0.06 $\mathrm{mm}$ in diameter. Large, lobular brain, with central neuropil displaced $8.22-18.18 \mathrm{U}$ posterior of anterior body edge (relative to total body length). Ventral mouth opening, positioned posterior of the brain, 20.48-34.69U from anterior edge (relative to total body length). Dorsal opening of male gonopore positioned $10-14 \mathrm{U}$ posterior to the neuropil (relative to total body length).

\section{Type material}

Holotype: one $1.57 \mathrm{~mm}$ long mature hermaphrodite (testis, ovary with eggs and seminal receptacles present) (ZMUC-POL-2384), beach in front of the Interuniversitary Institute for Marine Sciences (IUI) northwest of Eilat, Israel (N 29 $30.211^{\prime} \mathrm{E} 34^{\circ}$ 55.068), 9 meters deep, coral sand, collected by the authors 20.02.2014. Paratypes: Two mature and one juvenile specimens (section series, ZMUC-POL-2385, ZMUC-POL-2386, ZMUC-POL-2387), same locality as for holotype, (sampled on 14.02.2014, 16.02.2014 and 18.02.2014); one mature specimen collected by Mike Crezée (section series, ZMUC-POL-2388). 
Table 1 Measurements of the specimen of Lobatocerebrum riegeri n. sp. investigated in this study and distances of specific structures and organs to the anterior end of the body

\begin{tabular}{|c|c|c|c|c|c|c|}
\hline & $\begin{array}{l}\text { End of measurement } \\
\text { from the anterior tip }\end{array}$ & $\begin{array}{l}\text { Lobatocerebrum } \\
\text { riegeri II (CLSM, } \\
\text { holotype) }\end{array}$ & $\begin{array}{l}\text { L. riegeri } \\
\text { III (CLSM, } \\
\text { paratype) }\end{array}$ & $\begin{array}{l}\text { L. riegeri } \\
\text { IV (CLSM, } \\
\text { paratype) }\end{array}$ & $\begin{array}{l}\text { L. riegeri } \\
\text { I (juvenile, } \\
\text { CLSM, paratype) }\end{array}$ & $\begin{array}{l}\text { L. riegeri V } \\
\text { alive }(L M)\end{array}$ \\
\hline Total Length $[\mu \mathrm{m}]$ & & 1571,9 & 1078 & 1606 & 478 & 1646,6 \\
\hline Total Width [um] & & 40 & 79 & 55 & 66,5 & 51,4 \\
\hline Position of neuropile & & 247 & 196 & 204 & 132 & 250 \\
\hline \multicolumn{7}{|l|}{ Position of the brain } \\
\hline & Middle of the brain & 246 & 221 & 204 & 137,7 & 266 \\
\hline & Most anterior part & 177 & 179 & 159 & 108 & 215 \\
\hline & Most posterior part & 296 & 251 & 248 & 162 & 304 \\
\hline \multicolumn{7}{|l|}{ Position of the mouth } \\
\hline & Middle of the mouth & 322 & 374 & 344 & 182,3 & 330 \\
\hline & Most anterior part & 305 & 368 & 293 & 170 & 310 \\
\hline & Most posterior part & 343 & 403 & 375 & 203 & 350 \\
\hline Position of the male gonopore & & 593 & 476 & 557 & & 596 \\
\hline \multicolumn{7}{|l|}{ Position of the testis } \\
\hline & Middle of the testis & 758 & 576,5 & 712 & & 776 \\
\hline & Most anterior part & 725 & 556,5 & 691 & & 741 \\
\hline & Most posterior part & 787 & 596,5 & 732 & & 811 \\
\hline \multicolumn{7}{|l|}{ Position of the ovary } \\
\hline & Middle of the ovary & 1107 & 702,5 & 1053 & & 1150 \\
\hline & Most anterior part & 953 & 597,8 & 1036 & & 995 \\
\hline & Most posterior part & 1248 & 769,5 & 1070 & & 1304 \\
\hline \multicolumn{7}{|l|}{ Position of the seminal receptacles } \\
\hline & Middle of the receptacles & 1428 & 960,5 & 1350 & & 1510 \\
\hline & Most anterior part & 1424,9 & 944,5 & 1340 & & 1501 \\
\hline & Most posterior part & 1432,9 & 970 & 1360 & & 1519 \\
\hline
\end{tabular}

The measurements were taken from both live $(n=1)$ and fixed and mounted $(n=5)$ specimens, including one juvenile, as indicated. In the latter, neither the male nor the female gonad could be detected in transmitted light or CLSM-images. Measurements are taken in $\mu \mathrm{m}$ (in case of body length and width) and as $\mu \mathrm{m}$ from the anterior end of the respective animal to a specific point as indicated in the first and second column

\section{Etymology}

The species is named in memory of Reinhard M. Rieger, who discovered and described the first representative of Lobatocerebridae.

\section{Description}

Measurements of holotype are given in the text, ranges of all types are given in parentheses; juvenile is not included)

Lobatocerebrum riegeri has an elongated, cylindrical, entirely ciliated body, which appears slightly greenish due to the glandular epidermis (Fig. 9a). The total body length is $1.57 \mathrm{~mm}$ (varies between 1.08 and $1.6 \mathrm{~mm}$ in adults), the body width is $0,04 \mathrm{~mm}(0.04-0.06 \mathrm{~mm}$, Tables 1, 2). The rostrum is $305 \mu \mathrm{m}(293-368 \mu \mathrm{m}$, Fig. 9b); the uniform trunk extends for an additional $1266 \mu \mathrm{m}(710-1336 \mu \mathrm{m}$, Table 1). The brain is located dorsally in the rostrum $246 \mu \mathrm{m}(204-266 \mu \mathrm{m})$ from the anterior tip, extends for $119 \mu \mathrm{m}(30-44 \mu \mathrm{m})$ posteriorly and has an oval, but lobular appearance (two frontal and four posterior lobes embracing the central neuropil visible with LM, Fig. 9c, Tables 1, 2). The mouth opening is $322 \mu \mathrm{m}(330-374 \mu \mathrm{m})$ from the anterior tip; extends for $21(20-31 \mu \mathrm{m}$, Fig. 9d, Tables 1, 2) and the pharynx is heavily ciliated and supplied with several glands. The transitions from the fore- to the mid-gut $480 \mu \mathrm{m}(450-$ $580 \mu \mathrm{m})$ from the anterior tip and from the mid- to the hindgut $820 \mu \mathrm{m}$ from the anterior tip $(800-1300 \mu \mathrm{m})$ are marked by a decrease in diameter, sphincter muscles and change in ciliation pattern (strong in fore- and hindgut, weaker in mid-gut). No protonephridia were detected with the techniques applied (adults and juvenile). The male gonopore $593 \mu \mathrm{m}(476-596 \mu \mathrm{m})$ from the anterior tip and associated gland cells as well as one testis $758 \mu \mathrm{m}$ (576-758 $\mu \mathrm{m}$, Fig. 9a, Tables 1, 2) from the anterior tip are all located dorsally. In mature specimens, big, slightly 
Table 2 Comparisons of measurements and distances of specific structures and organs to the anterior tip of different species of Lobatocerebridae

\begin{tabular}{|c|c|c|c|c|c|c|}
\hline & $\begin{array}{l}\text { Lobatocerebrum } \\
\text { psammicola live }\end{array}$ & $\begin{array}{l}\text { L. } \\
\text { psammicola fixed }\end{array}$ & $\begin{array}{l}\text { Lobatocerebrum } \\
\text { sp. } 1\end{array}$ & $\begin{array}{l}\text { Lobatocerebrum } \\
\text { sp. } 2\end{array}$ & $\begin{array}{l}\text { Lobatocerebrum } \\
\text { riegeri }\end{array}$ & L. riegeri conclusions/remarks \\
\hline Total length $[\mathrm{mm}]$ & 3.0 & $2.0-2.2$ & 1.1 & 1.7 & $1.57(1.08-1.6[0.48])$ & $\begin{array}{l}\text { L. riegeri is shorter than L. psammicola and the other reported } \\
\text { specimens }\end{array}$ \\
\hline Total width $[\mathrm{mm}]$ & 0.11 & $0.07-0.08$ & 0.06 & 0.06 & $0.04(0.04-0.06[0.07])$ & $\begin{array}{l}\text { L. riegeri is thinner than the other species and reported specimens, } \\
\text { though not relative to the body length }\end{array}$ \\
\hline Relative width & 0.036 & $0.035-0.036$ & 0.055 & 0.035 & $0.025(0.025-0.038[0.15])$ & $\begin{array}{l}\text { L. riegeri is thinner than the other species and reported specimens, } \\
\text { though not relative to the body length }\end{array}$ \\
\hline $\begin{array}{l}\text { Position of the neuropile } \\
\text { [1-100U] }\end{array}$ & 9 & $7-12$ & 14 & 12 & $18.18(8.22-18.18$ [27.61]) & $\begin{array}{l}\rightarrow \text { displaced more posteriorly in } L \text {. riegeri than in } L \text {. psammicola and } \\
\text { the other reported specimens }\end{array}$ \\
\hline $\begin{array}{l}\text { Position of the brain } \\
{[1-100 U]}\end{array}$ & 9 & $7-12$ & 14 & 12 & $15.65(12.7-20.5[28.8])$ & \\
\hline $\begin{array}{l}\text { Position of the mouth } \\
{[1-100 U]}\end{array}$ & 14 & $10-17$ & 20 & 20 & $20.48(20.48-34.69[38.14])$ & $\begin{array}{l}\rightarrow \text { displaced more posteriorly in } L \text {. riegeri than in L. psammicola, } \\
\text { but in the same range as the other reported species }\end{array}$ \\
\hline $\begin{array}{l}\text { Position of the male } \\
\text { gonopore }[1-100 U]\end{array}$ & 38 & $30-36$ & $\begin{array}{l}\text { No measurements } \\
\text { provided }\end{array}$ & 31 & $37.72(34.68-44.16)$ & $\rightarrow$ range outside L. sp. 2 , but similar to L. psammicola \\
\hline $\begin{array}{l}\text { Position of the testis } \\
{[1-100 U]}\end{array}$ & $47-57$ & $46-56$ & $\begin{array}{l}\text { No measurements } \\
\text { provided }\end{array}$ & $35-43$ & $48.21(44.33-53.48)$ & $\begin{array}{l}\rightarrow \text { posterior to L. sp.2, but with the broad range similar to } \\
\text { L. psammicola }\end{array}$ \\
\hline $\begin{array}{l}\text { Position of the ovary } \\
{[1-100 U]}\end{array}$ & $58-63$ & & $\begin{array}{l}\text { No measurements } \\
\text { provided }\end{array}$ & $48-79$ & $70.42(65.17-70.42)$ & $\rightarrow$ too broad ranged to be diagnostic \\
\hline $\begin{array}{l}\text { Position of the seminal } \\
\text { receptacles }[1-100 U]\end{array}$ & 90,5 & $87-89$ & $\begin{array}{l}\text { No measurements } \\
\text { provided }\end{array}$ & 88 & $90.84(84.06-90.84)$ & $\rightarrow$ too broad ranged to be diagnostic \\
\hline
\end{tabular}

The measurements of Lobatocerebrum psammicola, L. sp. 1 and L. sp. 2 were taken from [8]. L. riegeri n. sp. (this study) was obtained from this study and translated in the units used by [8] (in 1-100U for the entire body length). For L. riegeri n. sp., all measurements are taken from fixed and mounted specimens in the following order: holotype [range of all adult specimens (juvenile)]. L. riegeri $\mathrm{n}$. sp. specimen III was excluded from the range given for body length and width, since it was compressed to a high degree, but was considered for the relative measurements 
Table 3 Compilation of features of the nervous system in representatives of different spiralian groups with previously proposed relationship to Lobatocerebrum riegeri n. sp

\begin{tabular}{|c|c|c|c|c|c|c|c|}
\hline & & \multicolumn{3}{|l|}{ ANNELIDA } & \multicolumn{3}{|l|}{ MOLLUSCA } \\
\hline & & LOBATOCERBRIDAE & SIPUNCULA & ORBINIIDAE & SOLENOGASTRES & CAUDOFOVEATA & GASTROPODA \\
\hline & & $\begin{array}{l}\text { Lobatocerebrum } \\
\text { riegeri n. sp. }\end{array}$ & $\begin{array}{l}\text { Phascoliun } \\
\text { strombus }\end{array}$ & Scoloplos armiger & Dorymenia sarsii & $\begin{array}{l}\text { Chaeoderma } \\
\text { japonicum }\end{array}$ & $\begin{array}{l}\text { Helminthope } \\
\text { psammibionta }\end{array}$ \\
\hline & $\begin{array}{l}\text { Location of the } \\
\text { ventral nerve cords }\end{array}$ & Intraepithelial & $\begin{array}{l}\text { Intraepithelial/ } \\
\text { subepidermal }\end{array}$ & Intraepithelial & Subepidermal & Subepidermal & $\overline{\text { Subepidermal }}$ \\
\hline \multirow[t]{3}{*}{ BRAIN } & Lobular structure & + & $?$ & + & - & + & + \\
\hline & Central neuropile & + & + & + & + & + & + \\
\hline & $\begin{array}{l}\text { Number of brain } \\
\text { commissures }\end{array}$ & 4 & 2 & 4 & 1 & 1 & 1 \\
\hline \multirow[t]{3}{*}{$\begin{array}{l}\text { NERVE CORDS OF THE } \\
\text { CENTRAL NERVOUS } \\
\text { SYSTEM }\end{array}$} & $\begin{array}{l}\text { Number of posterior } \\
\text { longitudinal nerve } \\
\text { cords }\end{array}$ & $\begin{array}{l}1 \text { pair }+1 \text { median } \\
\text { cord }\end{array}$ & 1 pair & 1 pair & $\begin{array}{l}2 \text { pairs }(+1 \\
\text { median cord) }\end{array}$ & 2 pairs & 2 pairs \\
\hline & $\begin{array}{l}\text { Median posterior } \\
\text { nerve cord }\end{array}$ & + & - & - & + & - & - \\
\hline & $\begin{array}{l}\text { Number of rostral } \\
\text { longitudinal nerve } \\
\text { cords }\end{array}$ & $2-9$ & 0 & 0 & - & - & 2 pairs \\
\hline \multirow{3}{*}{$\begin{array}{l}\text { GANGLIA AND } \\
\text { COMMISSURES ALONG } \\
\text { THE VENTRAL NERVE } \\
\text { CORD }\end{array}$} & $\begin{array}{l}\text { Total number of } \\
\text { ganglia }\end{array}$ & 2 pairs & $>2$ & $>2$ & $>2$ & $>2$ & $>2$ \\
\hline & $\begin{array}{l}\text { Nonganglionated } \\
\text { posterior } \\
\text { commissures }\end{array}$ & $>2$ & $?$ & $>2$ & $>2$ & $>2$ & $>2$ \\
\hline & $\begin{array}{l}\text { Presence of a } \\
\text { subpharyngeal } \\
\text { ganglion }\end{array}$ & + & + & + & + & + & + \\
\hline $\begin{array}{l}\text { PERIPHERAL NERVOUS } \\
\text { SYSTEM }\end{array}$ & & $\begin{array}{l}\text { Grid of distinct } \\
\text { longitudinal and } \\
\text { circular nerves }\end{array}$ & Nerve plexus & $\begin{array}{l}\text { Grid of pairwise arranged } \\
\text { longitudinal and several } \\
\text { circular nerves per segment }\end{array}$ & $?$ & $?$ & $?$ \\
\hline References & & This study & {$[57,73,74]$} & {$[75,76]$} & {$[40,41]$} & {$[40]$} & {$[43]$} \\
\hline
\end{tabular}


Table 3 Compilation of features of the nervous system in representatives of different spiralian groups with previously proposed relationship to Lobatocerebrum riegeri $\mathrm{n}$. sp

\begin{tabular}{|c|c|c|c|c|c|c|c|c|c|}
\hline & & \multicolumn{3}{|l|}{ NEMERTEA } & \multicolumn{3}{|c|}{ GNATHOSTOMULIDA } & \multirow{3}{*}{$\begin{array}{l}\text { PLATYHELMINTHES } \\
\text { CATENULIDA } \\
\text { Stenostomum } \\
\text { leucops }\end{array}$} & \multirow{3}{*}{$\begin{array}{l}\text { XENACOELOMORPHA } \\
\text { NEMERTODERMATIDA } \\
\text { Nemertoderma } \\
\text { westbaldi }\end{array}$} \\
\hline & & \multicolumn{2}{|c|}{ PALAEONEMERTEA } & \multirow{2}{*}{$\begin{array}{l}\text { ANOPLA } \\
\text { Lineus viridens }\end{array}$} & \multicolumn{2}{|c|}{ BURSOVAGINOIDEA } & \multirow{2}{*}{$\begin{array}{l}\text { FILOSPERMOIDEA } \\
\text { Pterognathia } \\
\text { meixneri }\end{array}$} & & \\
\hline & & $\begin{array}{l}\text { Cephalothrix } \\
\text { linearis }\end{array}$ & Procephalo-thrix linearis & & $\begin{array}{l}\text { Gnathostomula } \\
\text { peregrina }\end{array}$ & $\begin{array}{l}\text { Rastrognathia } \\
\text { macrostoma }\end{array}$ & & & \\
\hline & $\begin{array}{l}\text { Location of the } \\
\text { ventral nerve cords }\end{array}$ & Subepidermal & Subepidermal & Subepidermal & Intraepithelial & Intraepithelial & Intraepithelial & $\begin{array}{l}\text { ? (mainly } \\
\text { subepidermal) }\end{array}$ & $\begin{array}{l}\text { Intraepithelia to } \\
\text { subepidermal }\end{array}$ \\
\hline \multirow[t]{3}{*}{ BRAIN } & Lobular structure & + & + & + & - & $?(-)$ & - & - & - \\
\hline & Central neuropile & + & + & + & + & $?(+)$ & + & + & $\begin{array}{l}\text { - (only } \\
\text { commissures } \\
\text { formed) }\end{array}$ \\
\hline & $\begin{array}{l}\text { Number of brain } \\
\text { commissures }\end{array}$ & $>2$ & $>2$ & $>2$ & 1 & $?(1)$ & 1 & 1 & $\begin{array}{l}2 \text { rings (dorsally } \\
\text { connected) }\end{array}$ \\
\hline \multirow[t]{3}{*}{$\begin{array}{l}\text { NERVE CORDS OF THE } \\
\text { CENTRAL NERVOUS } \\
\text { SYSTEM }\end{array}$} & $\begin{array}{l}\text { Number of posterior } \\
\text { longitudinal nerve } \\
\text { cords }\end{array}$ & 1 pair & $\begin{array}{l}1 \text { pair }+1 \text { dorsal median } \\
+1 \text { ventral median cord }\end{array}$ & 1 pair & 1 pair & 1 pair & 1 pair & 1 pair & $\begin{array}{l}\text { - (thin fibres, but } \\
\text { no cords) }\end{array}$ \\
\hline & $\begin{array}{l}\text { Median posterior } \\
\text { nerve cord }\end{array}$ & - & + & - & $\begin{array}{l}+ \text { (just a short } \\
\text { piece) }\end{array}$ & $?(-)$ & - & - & - \\
\hline & $\begin{array}{l}\text { Number of rostral } \\
\text { longitudinal nerve } \\
\text { cords }\end{array}$ & $?$ & 4 & Approx. 8 pairs & - & $?$ & $\begin{array}{l}>3 \text { paired and } \\
2 \text { unpaired }\end{array}$ & - & - \\
\hline \multirow{3}{*}{$\begin{array}{l}\text { GANGLIA AND } \\
\text { COMMISSURES ALONG } \\
\text { THE VENTRAL NERVE } \\
\text { CORD }\end{array}$} & $\begin{array}{l}\text { Total number of } \\
\text { ganglia }\end{array}$ & $?$ & $?$ & 1 pair & 1 pair & ? (1 pair) & 1 pair & $?$ & $?$ \\
\hline & $\begin{array}{l}\text { Nonganglionated } \\
\text { posterior } \\
\text { commissures }\end{array}$ & $?$ & 1 & $?$ & 1 & $?(1)$ & $1(2)$ & $?$ & - \\
\hline & $\begin{array}{l}\text { Presence of a } \\
\text { subpharyngeal } \\
\text { ganglion }\end{array}$ & + & + & + & + & $?(+)$ & + & + & - \\
\hline $\begin{array}{l}\text { PERIPHERAL NERVOUS } \\
\text { SYSTEM }\end{array}$ & & $?$ & $\begin{array}{l}\text { Intraepidermal plexus } \\
\text { around the rhynchocoel }\end{array}$ & $\begin{array}{l}\text { Subepidermal plexus, } \\
\text { commissural plexus, } \\
\text { stomatogastric plexus, } \\
\text { proboscidial plexus }\end{array}$ & $\begin{array}{l}5 \text { longitudinal } \\
\text { nerves }\end{array}$ & $\begin{array}{l}6 \text { longitudinal } \\
\text { nerves }\end{array}$ & $\begin{array}{l}3 \text { dorsal } \\
\text { longitudinal } \\
\text { nerves }\end{array}$ & $?$ & $?$ \\
\hline References & & {$[42,48]$} & [42] & [77] & [78] & {$[17,79]$} & [17] & {$[46,80]$} & {$[81,82]$} \\
\hline
\end{tabular}

Details of the brain, the ventral nervous system, the stomatogastric nervous system and the peripheral nervous system are given in an attempt to reveal common features or possible apomorphies in

Lobatocerebridae. Presence of a character is labeled with +, absence with -, numbers and additional informations are given wherever possible. "?" indicates the lack of information in the references mentioned, while reinvestigations from this study (in the case of $L$. riegeri $\mathrm{n}$. sp.) and assumptions based on additional references are included by putting the assessment in brackets (+) or (-). Only species with previously [8-12] or recently [7] suggested relationship to Lobatocerebridae were considered. Insufficient information in one species was supplemented with closely related species, based on the literature acknowledged in the reference-row 
Table 4 Compilation of features of the nervous system in representatives of different annelid groups and Lobatocerebrum riegeri n. sp

\begin{tabular}{|c|c|c|c|c|c|c|c|}
\hline & & \multicolumn{6}{|l|}{ ANNELIDA } \\
\hline & & \multicolumn{6}{|c|}{ PREVIOUS "PROBLEMATICA", nOW ANNELIDA } \\
\hline & & \multicolumn{2}{|l|}{ LOBATOCEREBRIDAE } & \multirow{2}{*}{$\begin{array}{l}\text { DIURODRILIDAE } \\
\text { Diurodrilus sp. }\end{array}$} & \multirow{2}{*}{ ? } & \multicolumn{2}{|l|}{ SIPUNCULA } \\
\hline & & $\begin{array}{l}\text { Lobatocerebrum } \\
\text { riegeri n. sp. }\end{array}$ & $\begin{array}{l}\text { Lobatocerebrum } \\
\text { psammicola }\end{array}$ & & & Phascolion strombus & Siphonosoma australe \\
\hline & $\begin{array}{l}\text { Location of the } \\
\text { ventral nerve cords }\end{array}$ & Intraepithelial & Intraepithelial & Intraepithelial & Intraepithelial & Intraepithelial & Intraepithelial \\
\hline \multirow[t]{5}{*}{ BRAIN } & Lobular structure & + & + & $?$ & + & $?$ & $?$ \\
\hline & Central neuropile & + & + & + & + & + & + \\
\hline & $\begin{array}{l}\text { Number of brain } \\
\text { commissures }\end{array}$ & 4 & $?$ & 4 & $?$ & 2 & 1 \\
\hline & $\begin{array}{l}\text { Dorsal root (dorsal/ } \\
\text { ventral commissure) }\end{array}$ & $+(+/+)$ & $?$ & $+(+/+)$ & $?$ & $?$ & - (Not differentiated in this species) \\
\hline & $\begin{array}{l}\text { Ventral root (dorsal/ } \\
\text { ventral commissure) }\end{array}$ & $\begin{array}{l}+(+/+ \text {, individual } \\
\text { fibres spread out })\end{array}$ & $?$ & $+(+/+)$ & $?$ & $?$ & - (Not differentiated in this species) \\
\hline \multirow[t]{3}{*}{$\begin{array}{l}\text { NERVE CORDS OF THE } \\
\text { CENTRAL NERVOUS } \\
\text { SYSTEM }\end{array}$} & $\begin{array}{l}\text { Number of posterior } \\
\text { longitudinal nerve } \\
\text { cords }\end{array}$ & $\begin{array}{l}1 \text { pair }+1 \text { median } \\
\text { cord }\end{array}$ & $\begin{array}{l}1 \text { pair (+1 } \\
\text { median cord?) }\end{array}$ & 2 pairs & 1 pair & 1 pair & 1 pair (fused during development) \\
\hline & $\begin{array}{l}\text { Median posterior } \\
\text { nerve cord }\end{array}$ & + & $?$ & - & - & - & - \\
\hline & $\begin{array}{l}\text { Number of rostral } \\
\text { longitudinal nerve cords }\end{array}$ & $\begin{array}{l}2 \text { ventrolateral }+<7 \\
\text { additional, smaller ones }\end{array}$ & $2(?)$ & $>2$ & $?$ & 0 & 0 \\
\hline \multirow{3}{*}{$\begin{array}{l}\text { GANGLIA AND } \\
\text { COMMISSURES } \\
\text { ALONG THE VENTRAL } \\
\text { NERVE CORD }\end{array}$} & Total number of ganglia & 2 pairs & 2 pairs & 1 (fused pair) & $?$ & $>2$ & $>2$ (during development) \\
\hline & $\begin{array}{l}\text { Nonganglionated } \\
\text { posterior } \\
\text { commissures }\end{array}$ & $>2$ & 2 & $>2$ & 1 & $?$ & $>2$ (during development) \\
\hline & $\begin{array}{l}\text { Presence of a } \\
\text { subpharyngeal } \\
\text { ganglion }\end{array}$ & + & + & + & $?$ & + & + (during development) \\
\hline \multirow[t]{2}{*}{$\begin{array}{l}\text { STOMATOGASTRIC } \\
\text { NERVOUS SYSTEM }\end{array}$} & $\begin{array}{l}\text { Stomatogastric } \\
\text { nervous system }\end{array}$ & $\begin{array}{l}+(\text { ring around the } \\
\text { pharynx })\end{array}$ & $\begin{array}{l}+ \text { (ring around } \\
\text { the pharynx) }\end{array}$ & $\begin{array}{l}+ \text { (ring around the } \\
\text { esophagus) }\end{array}$ & $\begin{array}{l}+ \text { (nerve cells in the } \\
\text { pharyngeal epithelium) }\end{array}$ & $\begin{array}{l}+ \text { (ring around the } \\
\text { esophagus }\end{array}$ & $\begin{array}{l}+ \text { (ring around the esophagus, } \\
\text { during development) }\end{array}$ \\
\hline & $\begin{array}{l}\text { Origin of the } \\
\text { stomatogastric } \\
\text { nervous system }\end{array}$ & $\begin{array}{l}\text { Postpharyngeal } \\
\text { ganglion }\end{array}$ & $\begin{array}{l}\text { Postpharyngeal } \\
\text { ganglion }\end{array}$ & prebuccal ganglion & $?$ & brain (?) & brain (?) \\
\hline $\begin{array}{l}\text { PERIPHERAL NERVOUS } \\
\text { SYSTEM }\end{array}$ & & $\begin{array}{l}\text { Grid of distinct } \\
\text { longitudinal and } \\
\text { circular nerves }\end{array}$ & $?$ & $\begin{array}{l}1 \text { pair of longitudinal } \\
\text { nerves, several branches } \\
\text { for innervating organs }\end{array}$ & $\begin{array}{l}\text { Some nerves around } \\
\text { the pharynx and gut, } \\
\text { otherwise not present } \\
\text { or not described }\end{array}$ & Nerve plexus & $?$ \\
\hline References & & This study & [8-11] & [61] & {$[9,83]$} & {$[57,73]$} & [58] \\
\hline
\end{tabular}


Table 4 Compilation of features of the nervous system in representatives of different annelid groups and Lobatocerebrum riegeri n. sp

\begin{tabular}{|c|c|c|c|c|c|c|c|c|}
\hline & & \multirow{2}{*}{$\begin{array}{l}\text { DINOPHILIDAE } \\
\text { Dinophilus gyrociliatus }\end{array}$} & \multirow{2}{*}{$\begin{array}{l}\text { PROTODRILIDAE } \\
\text { Protodrilus sp. }\end{array}$} & \multirow{2}{*}{$\begin{array}{l}\text { PSAMMODRILIDAE } \\
\text { Psammodrilus fauveli }\end{array}$} & \multirow{2}{*}{$\begin{array}{l}\text { NEREIDIDAE } \\
\text { Platynereis sp. }\end{array}$} & \multirow{2}{*}{$\begin{array}{l}\text { CAPITELLIDAE } \\
\text { Capitella sp. }\end{array}$} & \multicolumn{2}{|l|}{ SERPULIDAE } \\
\hline & & & & & & & $\begin{array}{l}\text { Pomatoceros } \\
\text { lamarckii }\end{array}$ & Spirorbis cf. spirorbis \\
\hline & $\begin{array}{l}\text { Location of the } \\
\text { ventral nerve cords }\end{array}$ & Intraepithelial & Intraepithelial & Intraepithelial & Intraepithelial & Intraepithelial & Intraepithelial & Intraepithelial \\
\hline \multirow[t]{5}{*}{ BRAIN } & Lobular structure & - & - & + & + & + & - & + \\
\hline & Central neuropile & + & + & + & + & + & + & + \\
\hline & $\begin{array}{l}\text { Number of brain } \\
\text { commissures }\end{array}$ & 2 & 4 & 4 & 4 & 4 & 4 & 4 \\
\hline & $\begin{array}{l}\text { Dorsal root (dorsal/ } \\
\text { ventral commissure) }\end{array}$ & $?$ & $+(+/+)$ & $+(+/+)$ & $+(+/+)$ & $+(+/+)$ & $+(+/+)$ & $+(+/+)$ \\
\hline & $\begin{array}{l}\text { Ventral root (dorsal/ } \\
\text { ventral commissure) }\end{array}$ & $?$ & $+(+/+)$ & $+(+/+)$ & $+(+/+)$ & $+(+/+)$ & $+(+/+)$ & $+(+/+)$ \\
\hline \multirow[t]{3}{*}{$\begin{array}{l}\text { NERVE CORDS OF THE } \\
\text { CENTRAL NERVOUS } \\
\text { SYSTEM }\end{array}$} & $\begin{array}{l}\text { Number of posterior } \\
\text { longitudinal nerve } \\
\text { cords }\end{array}$ & 3 pairs + median cord & 1 pair & 1 pair & 1 pair & 1 pair & 1 pair & 1 pair \\
\hline & $\begin{array}{l}\text { Median posterior } \\
\text { nerve cord }\end{array}$ & + & - & - & - & + & + & - \\
\hline & $\begin{array}{l}\text { Number of rostral } \\
\text { longitudinal nerve cords }\end{array}$ & 0 & $\begin{array}{l}0 \text { (but } \\
\text { innervation } \\
\text { of tentacles) }\end{array}$ & 0 & 0 & 0 & $\begin{array}{l}0 \text { (but innervation } \\
\text { of tentacles) }\end{array}$ & $\begin{array}{l}0 \text { (but innervation } \\
\text { of tentacles) }\end{array}$ \\
\hline \multirow{3}{*}{$\begin{array}{l}\text { GANGLIA AND } \\
\text { COMMISSURES } \\
\text { ALONG THE VENTRAL } \\
\text { NERVE CORD }\end{array}$} & Total number of ganglia & $>2$ & $>2$ & $>2$ & $>2$ & $>2$ & $>2$ & 1 (in larvae) \\
\hline & $\begin{array}{l}\text { Nonganglionated } \\
\text { posterior } \\
\text { commissures }\end{array}$ & $>2$ & $>2$ & $>2$ & $>2$ & $>2$ & $>2$ & 1 (in larvae) \\
\hline & $\begin{array}{l}\text { Presence of a } \\
\text { subpharyngeal } \\
\text { ganglion }\end{array}$ & + & + & + & + & + & + & + \\
\hline $\begin{array}{l}\text { STOMATOGASTRIC } \\
\text { NERVOUS SYSTEM }\end{array}$ & $\begin{array}{l}\text { Stomatogastric } \\
\text { nervous system }\end{array}$ & $\begin{array}{l}+(\text { ring around the } \\
\text { pharynx) }\end{array}$ & $\begin{array}{l}+ \text { (ring around } \\
\text { the esophaus) }\end{array}$ & $\begin{array}{l}+ \text { (ring around the } \\
\text { esophagus, also } \\
\text { tracing the } \\
\text { esophagus) }\end{array}$ & $\begin{array}{l}+ \text { (ring around } \\
\text { the esophagus) }\end{array}$ & $\begin{array}{l}+ \text { (ring around } \\
\text { the esophagus) }\end{array}$ & $\begin{array}{l}+ \text { (fibre along the } \\
\text { gut, ring around the } \\
\text { esophagus) }\end{array}$ & - \\
\hline
\end{tabular}


Table 4 Compilation of features of the nervous system in representatives of different annelid groups and Lobatocerebrum riegeri n. sp

\begin{tabular}{|c|c|c|c|c|c|c|c|c|}
\hline & $\begin{array}{l}\text { Origin of the } \\
\text { stomatogastric } \\
\text { nervous system }\end{array}$ & $\begin{array}{l}\text { Brain (dorso-posterior } \\
\text { neuropile) }\end{array}$ & Brain & Buccal ganglion & Brain & Brain & Brain & - \\
\hline $\begin{array}{l}\text { PERIPHERAL NERVOUS } \\
\text { SYSTEM }\end{array}$ & & $\begin{array}{l}\text { Regular grid of } \\
\text { longitudinal and } \\
\text { circular nerves, nerve } \\
\text { plexus dorsal to the } \\
\text { ventral nervous system }\end{array}$ & $?$ & $?$ & $\begin{array}{l}\text { Grid of distinct } \\
\text { longitudinal and } \\
\text { circular nerves }\end{array}$ & $\begin{array}{l}\text { Grid of distinct } \\
\text { longitudinal and } \\
\text { circular nerves }\end{array}$ & $\begin{array}{l}\text { Circular nerves in } \\
\text { some segments }\end{array}$ & $\begin{array}{l}\text { Grid of distinct } \\
\text { longitudinal and } \\
\text { circular nerves }\end{array}$ \\
\hline References & & {$[14,84,85]$} & {$[55,86]$} & {$[87,88]$} & {$[70,89,90]$} & [91] & [92] & [92] \\
\hline
\end{tabular}

Details of the brain, the ventral nervous system, the stomatogastric nervous system and the peripheral nervous system are given in an attempt to reveal common features or possible apomorphies in

Lobatocerebridae. Presence of a character is labeled with + , absence with -, numbers and additional informations are given wherever possible. ? indicates the lack of information in the references mentioned, while

reinvestigations from this study (in the case of $L$. riegeri $\mathrm{n}$. sp.) and assumptions based on additional references are included by putting the assessment in brackets (+) or (-). Insufficient information in one species was

supplemented with closely related species, based on the literature acknowledged in the reference-row 
oval but irregular-shaped eggs can be found in the posterior region of the body $1107 \mu \mathrm{m}(702-1107 \mu \mathrm{m}$, Tables 1 , 2) from the anterior tip). Seminal receptacles, if present (one to three found in the specimens investigated), can be found in the posterior region of the body $1428 \mu \mathrm{m}$ (960$1428 \mu \mathrm{m}$, Table 1) from the anterior tip, opening laterally. The anus opens dorsally $1500 \mu \mathrm{m}(1000-1500 \mu \mathrm{m}$, Fig. 9e) from the anterior tip.

\section{Remarks}

Lobatocerebrum riegeri is smaller (1.08-1.6 $\mathrm{mm}$ in adults compared to $2.0-3.0 \mathrm{~mm}$ in adults of L. psammicola) and thinner (0.04-0.06 $\mathrm{mm}$ in adults compared to $0.07-$ $0.11 \mathrm{~mm}$ in L. psammicola) than the related species [8]. The brain is displaced more posterior (8.22-18.18 U (distance from anterior end to central neuropil relative to total body length) in adults compared to 7-12U in $L$. psammicola) and the mouth opening is displaced further posterior in the body than in the previously described species (12.7-20.5U in adults compared to $10-17 \mathrm{U}$ in $L$. psammicola). Further distinguishing Lobatocerebrum riegeri from its previously described relative is the fact that it has a different secrete in the unicellular adhesive glands (linearly arranged globular inclusions in the granules in the adhesive glands in L. riegeri as compared to linear, rod-shaped inclusions in L. psammicola). Additionally, the two localities the different species have been found in (North Carolina, USA for L. psammicola and Eilat, Israel for L. riegeri) are far apart from each other and therefore the presence of two species seems to be probable. Further studies also involving molecular data are needed to further support this hypothesis, but are unfortunately not available now.

\section{Discussion}

Function and origin of the unique muscular ring complex The characteristic annelid (and spiralian) muscular arrangement consists of an external circular and internal longitudinal muscle layer $[22,38]$. However, the pattern in Lobatocerebridae differs in having externally positioned longitudinal muscles sunken into the epidermis, and within those inner transverse muscles previously mistakenly interpreted as continuous circular muscles [8]. However, each of these ring complexes resembles a discontinuous muscular network, composed by transverse muscle fragments, which together form serially repeated, discontinuous muscular ring complexes interconnecting the longitudinal muscles. Peristaltic body movements normally caused by contraction of circular muscles where never observed in Lobatocerebrum riegeri; however, the transverse fragments neither seemed to operate independently, but most likely aid to stabilizing the body wall during contraction of the longitudinal fibers. The lack of ring complex muscles in the rostrum on the other hand seems to allow for the high flexibility of the long rostral area in L. riegeri (Fig. 1b, e-g, Additional file 1). A flexibility which otherwise would have been prevented due to their different interconnecting composition compared to regular spiralian circular muscles, located external of the longitudinal muscles, even along the long rostrum of meiofaunal animals such as a the filospermoid Gnathostomulida [17] and catenulid Platyhelminthes ([39], Table 3). Since a similar muscular solution to both granting flexibility of the rostrum and stabilizing the trunk is not found in other annelids (or sipunculids), the muscular ring complex is considered a unique apomorphy of Lobatocerebridae.

\section{The paradox of a complex brain in a simple animal}

Lobular or compartmentalized, ganglionated brains are commonly found in macroscopic representatives of Spiralia and other metazoan groups (e.g. [18, 40, 41]), but interstitial animals generally do not show such a complex architecture (e.g. [16, 29], Tables 3, 4). However, some interstitial species of nemerteans [42], molluscs (especially in several wormlike gastropods such as Helminthope [43], Rhodope [44], and Pseudovermis [45]) and catenulids [46] also show some compartmentalization of the brain having, for example, visual and olfactory centers (Table 3). Another representative with a ganglionated brain is the enigmatic interstitial "worm" Jennaria pulchra (Figure 3a in [9]), which is described as representing many plesiomorphies of the trochozoan body plan [47] and possibly being an annelid [9]. Different compartments or lobes of the brain are normally related to processing of different sensory stimuli, yet all conspicuous sensory organs such as eyes, sensory appendages or olfactory nuchal organs are lacking in Lobatocerebridae. Moreover, the indistinct gut content and simple alimentary tract and behavior indicates that Lobatocerebrum sp. is an unselective deposit feeder. Though no sensory structures are found adjacent to, or directly connected to specific regions in the brain, it is still striking how the anterior rostrum is strongly innervated with nerves connected to various parts of the brain. Hence, though unlikely, the glandular secretion or the stimuli of the scattered sensory cells may in fact be processed in a much more organized manner and their signaling complexity exceed our expectations. Nonetheless, the complex lobular architecture of the brain in $L$. riegeri seems a functional paradox.

\section{Systematic importance of longitudinal nerve configuration}

Annelid central nervous systems vary in numbers of main longitudinal nerves, from one ventro-median cord to seven or more ventral nerves (Table 4, [21]). Based upon developmental studies and a broad comparison across Annelida, five ventral cords have been proposed as the ancestral pattern [15], yet this proposed character 
evolution was never traced upon a phylogenetic tree. The pattern of five nerves is made up of one pair of ventral, one pair of lateroventral and one median cord. The latter is revealed during neurogenesis in several annelids, and has been found in most interstitial annelids, possibly being an annelid apomorphy. However, it is only found elsewhere in Spiralia in a few exceptional cases (and with somewhat different configuration) (Solenogastres [40], some Nemertea [48], Table 3). According to a parsimonious tracing on the latest Spiralian tree [7] one pair of widely separated ventral cords would be the plesiomorphic state of Spiralia (Table 3 and references therein). Likewise, the basi- or intraepidermal position of the nervous system has also been regarded a plesiomorphic trait in Spiralia [49] as well as in Annelida such as now exemplified by the early branching annelid lineage Oweniidae [50-52] opposed to the derived subepidermal position found in many crown group annelids [53, 54]. However, intraepidermal nerve cords have also been found in Siboglinidae (Worsaae K, Rimskaya-Korsakova, NN, Rouse, GW: Neural reconstruction of bone-eating Osedax spp. (Annelida) and evolution of the siboglinid nervous system, submitted) as well as several interstitial annelids [19, 25, 54], showing considerable variance throughout evolution. The intraepidermal position of the paired ventral cords of Lobatocerebrum may hereby not be phylogenetically informative, whereas its additional median cord may be an annelid apomorphy. The two widely separated main nerve cords do not resemble a "typical" annelid pattern, but also do not dispute such a relationship, since such a pattern is also found in several other interstitial annelids such as Dinophilidae [15], Protodrilidae $[29,55]$, and Nerillidae [56].

Lobatocerebrum also possess two prominent and several additional long rostral nerves extending from the posteriorly displaced brain to the tip of the animal ([8], this study). This pattern is not found in any other annelids, which normally have the brain located anteriorly [28]. A similar pattern is found in a few examples of distantly related interstitial spiralians among Mollusca, Nemertea, Gnathostomulida, Catenulida (for details see Table 3) but has most likely arisen by convergence.

\section{Lobatocerebrum - an unsegmented annelid?}

The ventral nervous system in annelids most commonly consists of longitudinal nerve cords linked by ganglionated, serially arranged commissures, correlated with other serially repeated structures to form segments [49]. However, a clear outer segmentation as well as regularly distributed segmental paired ganglia are lacking in several groups recently assigned to annelids such as Diurodrilidae, Sipuncula, Echiura Siboglinidae and now also demonstrated for Lobatocerebrum riegeri. A similar layout to that of $L$. riegeri only having two pairs of subpharyngeal ganglia is also found in other spiralian groups (e.g. Gnathostomulida, Catenulida, for more details see Table 3), although the posterior commissures found in L. riegeri (ganglionated and non-ganglionated) are often not described or irregularly distributed (Table 3). Besides the low number of ganglia, there is no correlation of the commissural distribution with that of the few observed nephridia in L. psammicola $[8,9]$ nor with any other organ system in L. riegeri, which means that Lobatocerebrum cannot be regarded as segmented at present. This emphasizes, however, that more detailed studies of the developmental pattern in Lobatocerebridae are needed to check for signs of segmentation during ontogeny as found in Echiura and partly in Sipuncula $[57,59]$.

\section{A grid-like peripheral nervous system supporting a ventralized central nervous system may be a Spiralian plesiomorphy}

The peripheral nervous system is, especially in spiralians with a ventralized central nervous system, supposed to provide sufficient support and innervation for (sensory) organs in the periphery of the body [49]. Especially sensory cilia and glands are often abundantly distributed in the epidermis of interstitial animals far from the ventral nerve cords and the brain, as can be demonstrated in nearly all spiralian groups [60]. In annelids, the peripheral nervous system is often formed as an irregular grid constituted by longitudinal, oblique and circular nerves [21], relatively similar to those present in L. riegeri, though the pattern here appeared more regular and with the longitudinal nerves projecting directly from the neuropil rather than from the nerve cords. Moreover, this is the general pattern for several spiralians, so it cannot be viewed as a diagnostic trait for annelids (see Tables 3 and 4 for details). Supplementing or even replacing this grid, nerve plexi are found around specific organs, most often adjacent to the (male) reproductive organs or the mouth opening in nearly all groups considered for this comparison (see Tables 3 and 4 for details). However, since the grid is generally built from single (or few) fibres, the record of peripheral nervous system architecture especially among interstitial animals is rather incomplete.

\section{Function and origin of the long-necked frontal glands}

The frontal glands in Lobatocerebrum are among the diagnostic features of this group; the elongated ducts of the prominent glands can neither be found in other annelid groups (with the exception of Diurodrilidae [61]) nor in the majority of other spiralian groups. However, supposedly similar structures are present in catenulid Platyhelminthes (personal observation) and probably also in a few exceptional nemerteans and gnathostomulids 
(W. Sterrer, personal observation). The function of these glands is still unclear, though two options seem most likely: i) the secretion of these glands is used to produce a mucus layer to facilitate ciliary gliding; ii) the secretion is used to bind substances (e.g. pheromones or other chemical compounds) from the environment and thereby enhance the animal's ability to sense the environment and possibly even follow a chemical lead. However, though olfactory organs have been described for many invertebrates $[62,63]$, with annelids generally having ciliated nuchal organs [64-66], those are rarely glandular or resembling the structure of the frontal glands, why this hypotheses clearly needs further testing.

\section{Origin of meiofaunal characteristics of Lobatocerebridae}

Lobatocerebridae has been proposed to originate from a macroscopic, presumably annelid (or annelid-like) ancestor by progenesis (somatic arrest during larval or juvenile development due to early maturation [67]) $[8,9,11]$. This idea was based on its acoelomic condition and the presence of characters also present in annelid or spiralian larvae, such as complete ciliation, an intraepithelial nervous system, protonephridia and a rather simple formation of both musculature and ventral nervous system $[8,9,11]$. No single extant macrofaunal lineage possesses juveniles resembling adult Lobatocerebridae; however, the noted features are also common in other meiofaunal representatives of annelids, molluscs, nemerteans and platyhelminths (see Tables 3 and 4, and references herein for details), where progenesis is often seen as the most plausible pathway along which these interstitial animals have derived from a macroscopic ancestor [67]. Conversely, most of these features are also present in the early branching meiofaunal spiralian lineages (Gnathifera, Platyhelminthes, Gastrotricha) and were, according to the latest Spiralian topology, proposed to resemble spiralian plesiomorphies [7]. So when these traits are found in adult meiofauna they may not necessarily reflect an ancestry from a larval or juvenile stage, but could instead represent plesiomorphic states - or as a third alternative, gradual adaptations (reversals) to the constraints of the space-restricted interstitial environment $[11,16,30,31]$.

Meiofaunal spiralians generally have few nerve cords spaced far apart (rather than midventrally fused/condensed), and possess a body wall musculature spread out as a regular grid (rather than having the longitudinal muscles organized into four or fewer bundles, see Tables 3 and 4 and references therein for details). Besides this pattern possibly being the ancestral spiralian condition, there may exist 'universal constraints' on the functionally optimal neuromuscular design when being of microscopic size and with limited cell number, and given the evolutionary toolbox within Spiralia. Hence, the organization of the neuromuscular system may be more directly dependent on e.g., size, ciliary pattern or acoelomatic condition (e.g. as for the mesodermal blood vascular system and protonephridia $[11,68,69])$ in a way we haven't calculated for. Alternatively (or in addition), the condensation of muscles and nerves into bundles is a pattern often realized during development of annelids and certain spiralians (e.g., [70-72]), and although there is currently no way of testing this statement, the lack of condensation in Lobatocerebrum may also be seen as an evolutionary arrest in somatic development (at least of these specific somata) and hereby as a sign of paedomorphic origin rather than gradual adaptation. However, in the recent phylogenomic study placing Lobatocerebrum within Annelida [7], the exact position is not well supported, which is why its descend from either macrofaunal or a meiofaunal ancestor cannot be traced with conviction.

\section{Conclusion}

Although Lobatocerebrum was shown to be an annelid in a recent phylogeny [7], previous studies also suggested similarities to other spiralian groups such as Platyhelminthes, Nemertea, Mollusca and Gnathostomulida $[8,10,11]$. Conducting a detailed study of Lobatocerebrum riegeri with several complementary microscopical techniques revealed details of the musculature, the nervous system and the glandular system and allowed for a detailed description of Lobatocerebrum riegeri next to the previously described $L$. psammicola. Yet, L. riegeri is very similar to $L$. psammicola, both representing conservative spiralian patterns and a combination of traits diagnosing it as an annelid. Most features of the neuromuscular system revealed in L. riegeri by CLSM and TEM are not in themselves diagnostic to annelids and can either likewise be found in other groups or be unique for Lobatocerebridae. While these features on their own cannot reveal significant information about relationships within and between the spiralian groups, the combination of traits such as a nervous system with a complex brain with several commissures, a prominent median nerve cord and several ganglionated commissures, as well as a glandular, multiciliated epidermis and gliointerstitial system [10] together support an affinity to Annelida.

It is not possible to depict neither from the phylogenetic position nor morphological traits whether Lobatocerebridae originated through paedomorphosis or gradual miniaturization from a macrofaunal ancestor as an adaptation to the interstitial environment - or may even have retained plesiomorphic traits. Nonetheless, the lack of specific resemblance to any juvenile annelid relatives indicates a much more complex evolutionary history than what can be explained by a one-step progenetic evolutionary process. Further studies on the development of organ systems such as the musculature and the nervous system 
may prove useful for accessing the origin of Lobatocerebridae. Nonetheless, this study demonstrates that with Lobatocerebridae being annelids [7], Annelida displays an extreme evolutionary plasticity of the neuromuscular system, which is otherwise regarded as highly conservative throughout metazoan evolution.

\section{Methods \\ Sampling}

Specimens used for this study were collected in Eilat, Israel, from sand collected from a small $(0.5 \times 0.5 \mathrm{~m})$ sand patch between coral blocks at 8.5-9 m depth approximately $100 \mathrm{~m}$ southwest of the main pier of the Interuniversitary Institute for Marine Sciences (IUI, N $29^{\circ}$ $30.211^{\prime}$ E $34^{\circ}$ 55.068). Animals were extracted and anesthetized using an isotonic magnesium chloride solution: The upper $2-5 \mathrm{~cm}$ of sampled sand was mixed with this solution, and the water with floating particles and anesthetized animals decanted through $63 \mu \mathrm{m}$ meshes with seawater. Revitalized animals were sorted from the petri dish using dissecting compound microscopes. A total of nine specimens was found, examined and afterwards fixed for the techniques described below as well as for molecular analysis.

\section{Behavioral studies}

Animals were observed with a dissecting scope in a petri dish prior to being transferred to an object slide in seawater under cover for examination and imaging in a compound microscope with a mounted camera or a video recorder. For later relaxation, a weak $\mathrm{MgCl}_{2}$-solution was added to the slide. Movies were later analyzed in relation to the morphological studies and interpretation.

\section{Histology, light microscopy (LM) and transmission electron microscopy (TEM)}

Specimens were carefully anesthetized with isotonic magnesium chloride and afterwards fixed with $2 \%$ glutaraldehyde in $0.1 \mathrm{M}$ osmolarity-adjusted cacodylate buffer over night at room temperature (RT) and afterwards rinsed and stored in $0.1 \mathrm{M}$ cacodylate buffer. The animals were postfixed in $2 \% \mathrm{OsO}_{4}$ in $0.05 \mathrm{M}$ $\mathrm{K}_{3} \mathrm{FeCN}_{6}$-solution for $1 \mathrm{~h}$ and before embedding in Araldite Epon-812 using standard protocol and polymerization for $20-24 \mathrm{~h}$ at $50^{\circ} \mathrm{C}$.

For TEM-analysis, the block was trimmed to the object and sectioned into $40 \mathrm{~nm}$ sections using a Leica EM UC7 ultratome (LEICA MICROSYSTEMS, Wetzlar, Germany). Ultrathin section were mounted on Formvarcoated $2 \times 1 \mathrm{~mm}$ slot grids, contrasted with $2 \%$ uranyle acetate- and $4 \%$ lead citrate-solution and examined using a JEOL JEM 1010-Transmission Electron Microscope (TEM, JEOL Ltd., Tokyo, Japan) in combination with a digital GATAN OneView camera (GATAN, INC.,
Pleasanton, CA, United States). The fixation and preparation caused artifacts such as the slight separation of the epidermis from the internal organs of the animal.

\section{Immunohistochemistry and CLSM}

Specimens were carefully anesthetized with isotonic magnesium chloride and afterwards fixed in $3.7 \%$ paraformaldehyde in phosphate buffered saline (PBS) for 1 to $2 \mathrm{~h}$ at $\mathrm{RT}$, followed by several rinses in PBS and storage in PBS with $0.05 \% \mathrm{NaN}_{3}$. For the investigation of muscular, nervous, glandular and ciliary system quadruple stainings were applied, including F-actin staining (Alexa Fluor 488-labelled phalloidin, INVITROGEN, Carlsbad, USA), DNA-staining (405 nm fluorescent DAPI) and immunostaining (monoclonal mouse anti-acetylated $\alpha$-tubulin (SIGMA T6793, St. Louis, USA), polyclonal mouse antisynapsin 1 (3C11 (anti SYNORF1, DEVELOPMENTAL STUDIES HYBRIDOMA BANK, Iowa, USA) and antityrosinated tubulin (SIGMA T9028), polyclonal rabbit anti-serotonin (5-HT, SIGMA S5545) and anti-FMRFamide (IMMUNOSTAR 20091, Hudson, USA)). Prior to adding the primary antibody-mix, the samples were pre-incubated with $0.1 \%$ PBT (PBS + $0.1 \%$ Triton-X, $0.05 \%$ NaN3, $0.25 \%$ $\mathrm{BSA}$, and $10 \%$ sucrose) for $2 \mathrm{~h}$. Afterwards, samples were incubated for up to $24 \mathrm{~h}$ at RT in the primary antibodies mixed 1:1 (in a final 1:200 concentration (or 1:50 for antisynapsin 1)). Subsequently, specimens were rinsed in $0.1 \%$ PBT three to six times and incubated with the appropriate secondary antibodies conjugated with fluorochromes (also mixed 1:1 in a final concentration of 1:200; goat anti-mouse labeled with CY5 (JACKSON IMMUNO-RESEARCH, West Grove, USA, 115-175-062), goat anti-rabbit labeled with TRITC (SIGMA T5268)) for up to $24 \mathrm{~h}$ at RT. This step was followed by several rinses in $0.1 \%$ PBT and postincubation for $60 \mathrm{~min}$ in Alexa Fluor 488-labeled phalloidin (0.33 $\mathrm{M}$ in $0.1 \% \mathrm{PBT})$. Thereafter, specimens were rinsed in PBS (without NaN3) and mounted in Fluoromount-G with DAPI (SOUTHERN BIOTECHNOLOGY ASSOCIATES, Inc., Alabama, USA) or Vectashield with DAPI (VECTOR LABORATORIES, Burlingame, USA).

The mounted specimen were scanned using a Olympus Fluoview FV-1000 confocal laser scanning microscope (of K. Worsaae, University of Copenhagen, Denmark), with the acquired z-stacks of scans being either projected into 2D-images or analyzed three-dimensionally using IMARIS 7.1 (BITPLANE SCIENTIFIC SOFTWARE, Zürich, Switzerland). This software package was also used to conduct the measurements presented in the following text ( $n=$ number of specimens analyzed; $r=$ body region (1 - from the anterior tip to the mouth opening, 2 - from the mouth opening to the male gonopore, 3 - from the male gonopore to the ovary, 4 - from the ovary to the posterior tip of the animal); $m=$ number of measurements per region). 


\section{Measurements}

All measurements on live animals were taken in Adobe Photoshop after the images were acquired using a standardized scale bar, as was the procedure for measurements taken from TEM-pictures. Measurements from CLSM-image stacks were conducted in Imaris 7.1 using the Measurement-tool in Section-mode. For comparison with the measurements in Rieger [8], distances from the rostral tip to specific organ systems as well as body width and length were calculated in units (U), the entire body length being $100 \mathrm{U}$.

\section{Photoshop and Illustrator}

Contrast and brightness of all two-dimensional projections of confocal data and pictures of TEM-sections were adjusted in Adobe Photoshop CC 2015. Schematic drawing as well as plate-assembly was performed in Adobe Illustrator CC 2015.

\section{Additional file}

\section{Additional file 1: Motility pattern and details of the adult}

Lobatocerebrum riegeri $\mathbf{n}$. sp. This movie shows combined clips of alive Lobatoerebrum riegeri $\mathrm{n}$. sp. indicating both morphological specificities such as the pharynx and brain and motility patterns. (MP4 116178 kb)

\section{Abbreviations}

ac: anterior cilia; adnc: anterio-dorsal nerve cord; adlnc: anterior dorso-latera nerve cord; afg: anterior frontal gland; ag: adhesive granule; amf: anterior point of muscle fusion; an: anus; anc: anterior nerve cord; avnc: anterio-ventral nerve cord; avlnc: anterior ventro-lateral nerve cord; bl: basal lamina; br: brain; brc: brain cell; bsm: brain supporting muscle; c: cilium; c1-4: commissures 1-4; cg: ciliated gland cell; cmds: circular muscle of the digestive system; dcn: dorsoanterior commissure of the central neuropil; dfg: frontal gland ducts; dllm: dorsolateral longitudinal muscle; dlm: dorsal longitudinal muscle; e13: egg 1-3; ec: cili of an epidermis-cell; fpg1-2: FMRFamidergic perikarya of the postharyngeal ganglia 1 and 2; gd: opening of the frontal glands; go: glandular opening; gv: glandular vesicle; hg: hindgut; ksg: kidney-shaped gland cell; ladnc: lateral branch of the anterio-dorsal nerve cord; lavnc: lateral branch of the anterio-ventral nerve cord; Ica: major caudal lobes; Ici: minor caudal lobes; Ig: lateral ganglion; IIm: lateral longitudinal muscle; Imds: longitudinal muscle of the digestive system; In: lateral nerve; Inn: lateral peripheral nerve; Ipnp: lateral projection of the neuropil; Ir: rostral lobe; Ira: major rostral lobe; Irl: lateral rostral lobe; mg: male gonopore; mgg: male gonopore gland; mgp: perikaryon associated with the male gonopore; mlca: median nerve and connections from the dorsal commissure to the nerves of the major caudal lobes; mig: midgut; mnc: median nerve cord; mo: mouth opening; mrn: median rostral nerve; ne: epidermal nucleus; nlca: nerve of the major caudal lobe; nlci: nerve of the minor caudal lobe; nlra: nerve of the major rostral lobe; nlri: nerve of the lateral minor rostral lobe; nlrm: nerve of the median minor rostral lobe; nlrl: nerve of the lateral rostral lobe; np: neuropil; nrmg: nerve ring around the male gonopore; pcg: projection of the ciliated gland cell; pfg: posterior frontal gland; pg1-2: postpharyngeal ganglion 1-2; ph: pharynx; phg: pharyngeal gland; pln: peripheral longitudinal nerve; pp: posterior projection; ptg: projection of the tubular gland cell; rs: seminal receptacles; rsg: rod-shaped granules; sc: shortened cilium; snr: stomatogastric nerve ring; sp: perikarya of the stomatogastric nerve ring; spc: serotoninergic cell; spd: spermioduct; spf: sperm filaments; sph1-6: sphincter 1-6; ss: sensoria; ssm: star-shaped muscle; ssn: sickle-shaped nucleus; t: testis; tc: terminal commissure; tg: tubular glandl; tmr: transverse muscle ring complex; tpn: transverse ring of the peripheral nervous system; ts: tubulinergic sheath; tst: tubulinergic strands; vcn: ventral commissures of the neuropil; vllm: ventrolateral longitudinal muscle; vIm: ventral longitudinal muscle; vlnc: ventral longitudinal nerve cord.

\section{Competing interests}

The authors declare that they have no competing interests.

\section{Authors' contributions}

AK, NB and KW drafted the study. All authors (AK, NB, WS and KW) sampled the animals. AK, NB and KW conducted the laboratory experiments. KW and AK drafted the manuscript. All authors (AK, NB, WS and KW) contributed to the manuscript and approved of the final version.

\section{Acknowledgements}

The authors want to express their thanks to ASSEMBLE, who supported the study with the grant LOBATO ("Evolution of two enigmatic invertebrate families with proposed annelid affinity - the Lobatocerebridae and Nerillidae") for a trip to Eilat, Israel to collect the animals this study is mainly based on. The laboratory work as well as salaries of AK and NB was financed by the Villum Foundation (Grant Nr. 102544 to KW). Furthermore, we like to thank Gunde Rieger for continuous support with both material and discussion about Lobatocerebridae. Additionally, we want to thank Willi Salvenmoser and Peter Ladurner for fruitful discussions about the glandular epidermis of L. riegeri $\mathrm{n}$. sp. Lis Munk Frederiksen is hereby acknowledged for help with sectioning of embedded material for ultrastructural analysis. We highly appreciated all comments and discussion by Christopher Laumer and Gonzalo Giribet concerning the animal's phylogenetic position. Finally, we want to thank the reviewers and editor for their careful assessment and detailed comments that improved the manuscript.

\section{Author details}

${ }^{1}$ Marine Biological Section, Department of Biology, University of Copenhagen, Universitetsparken 4, 1st floor, 2100 Copenhagen E, Denmark. ${ }^{2}$ Bermuda Natural History Museum, Flatts, Bermuda, USA.

Received: 30 July 2015 Accepted: 4 November 2015 Published online: 10 December 2015

\section{References}

1. Dunn CW, Hejnol A, Matus DQ, Pang K, Browne WE, Smith SA, et al. Broad phylogenomic sampling improves resolution of the animal tree of life. Nature. 2008;452:e06614.

2. Giribet G, Sørensen MV, Funch P, Kristensen RM, Sterrer W. Investigations into the phylogenetic position of Micrognathozoa using four molecular loci. Cladistics. 2004;20:1-13.

3. Bourlat SJ, Nielsen C, Economou AD, Telford MJ. Testing the new animal phylogeny: a phylum level molecular analysis of the animal kingdom. Mol Phylogenet Evol. 2008;49(1):23-31. doi:10.1016/j.ympev.2008.07.008.

4. Zrzavy J, Mihulka S, Kepka P, Bezdek A, Tietz D. Phylogeny of the Metazoa based on morphological and 185 ribosomal DNA evidence. Cladistics. 1998;14:249-85.

5. Jenner RA, Littlewood DTJ. Problematica old and new. Philos Trans of the Royal Soc Series B. 2008;363:1503-12.

6. Haszprunar G, Rieger RM, Schuchert P: Extant "Problematica" within or near the Metazoa. In The early evolution of metazoa and the significance of problematic taxa. Volume 95. Edited by Simonetta AM, Conway Morris S. Cambridge: Cambridge University Press, New York; 1991:99-105.

7. Laumer CE, Bekkouche N, Kerbl A, Goetz F, Neves RC, Sørensen MV, Kristensen RM, Hejnol A, Dunn CW, Giribet G, Worsaae K: Spiralian Phylogeny Informs the Evolution of Microscopic Lineages. Curr Biol 2015; 25(15):2000-2006

8. Rieger RM. A new group of interstitial worms, Lobatocerebridae nov. fam. (Annelida) and its significance for metazoan phylogeny. Zoomorphologie. 1980;95:41-84

9. Rieger RM. Neue Organisationstypen aus der Sandlückenraumfauna: die Lobatocerebriden und Jennaria pulchra (New interstitial taxa of vermiform Bilateria). Verh Dtsch Zool Gesellschaft. 1991;84:247-59.

10. Rieger RM. Fine structure of the body wall, nervous system, and digestive tract in the Lobatocerebridae Rieger and the organization of the gliointerstitial system in Annelida. J Morphol. 1981;167:139-65.

11. Rieger RM. Comparative ultrastructure and the lobatocerebridae: keys to understand the phylogenetic relationship of Annelida and the acoelomates. In: Westheide W, Hermans CO, editors. The Ultrastructure of Polychaeta, 4. Stuttgart, New York: Gustav Fisher Verlag; 1988. p. $373-82$. 
12. Haszprunar G. The Mollusca: coelomate turbellarians or mesenchymate annelids? In: Taylor JD, editor. Origin and evolutionary radiation of the Mollusca. Oxford: Oxford University Press; 1996. p. 1-28.

13. Kristensen RM. Loricifera, a new phylum with aschelminthes characters from the meiobenthos. Z Zool Syst und Evolutions-Forschung. 1983;21:163-80

14. Jenner RA, Littlewood DTJ. Invertebrate problematica: kinds, causes, and solutions. In: Telford MJ, Littlewood DTJ, editors. Animal evolution: genomes, fossils, and trees. Oxford: Oxford University Press; 2009. p. 107-26.

15. Müller MCM, Westheide W. Comparative analysis of the nervous systems in presumptive progenetic dinophilid and dorvilleid polychaetes (Annelida) by immunohistochemistry and CLSM. Acta Zool (Stockholm). 2002;83:33-48.

16. Rundell RJ, Leander BS. Masters of miniaturization: convergent evolution among interstitial eukaryotes. BioEssays: news and reviews in mol, cell and dev biol. 2010;32:430-7.

17. Sterrer W, Sørensen MV. Gnathostomulida. Handbook of Zoology. 2015. p. $135-96$.

18. Richter S, Loesel R, Purschke G, Schmidt-Rhaesa A, Scholtz G, Stach T, et al. Invertebrate neurophylogeny: suggested terms and definitions for a neuroanatomical glossary. Frontiers in Zool. 2010;7:1-49.

19. Purschke G, Purschke G, Purschke G, Purschke G. On the ground pattern of Annelida. Org Divers Evol. 2002;2:181-96.

20. Filippova AV, Tzetlin AB, Filippova AV, Filippova AV. Muscular system in polychaetes (Annelida). Hydrobiologia. 2005;535-536:113-26.

21. Müller MCM. Polychaete nervous systems: ground pattern and variation - $\mathrm{CLS}$ microscopy and the importance of novel characteristics in phylogenetic analysis. Integr Comp Biol. 2006;46:125-33.

22. Tzetlin AB, Filippova AV. Muscular system in polychaetes (Annelida). Hydrobiologia. 2005;536(535):113-26. Morphology, molecules, evolution and phylogeny in Polychaeta and related taxa.

23. Purschke G, Müller MCM. Evolution of the body wall musculature. Integr Comp Biol. 2006;46:497-507.

24. Tzetlin AB, Zhadan A, Ivanov I, Müller MCM, Purschke G. On the absence of circular muscle elements in the body wall of Dysponetus pygmaeus (Chrysopetalidae, "Polychaeta", Annelida). Acta Zool (Stockholm). 2002;83:81-5.

25. Tzetlin AB, Dahlgren T, Purschke G. Ultrastructure of the body wall, body cavity, nephridia and spermatozoa in four species of the Chrysopetalidae (Annelida, "Polychaeta"). Zool Anz. 2002;241:37-55.

26. Harzsch S. Neurophylogeny: Architecture of the nervous system and a fresh view on arthropod phyologeny. Integr Comp Biol. 2006;46:162-94.

27. Butler $A B$, Molnár Z. Development and evolution in nervous systems: development and evolution of ideas. Trends Neurosci. 1998;21:177-8.

28. Reichert $\mathrm{H}$. Evolutionary conservation of mechanisms for neural regionalization, proliferation and interconnection in brain development. Biol Lett. 2009:5:112-6.

29. Orrhage L, Müller MCM. Morphology of the nervous system of Polychaeta (Annelida). Hydrobiologia. 2005;536(535):79-111. (Morphology, molecules, evolution and phylogeny in Polychaeta and related taxa).

30. Boaden PJS. Meiofauna and the origins of the Metazoa. Zool J Linnean Soc. 1989;96:217-27.

31. Curini-Galletti $M$, Artois $T$, Delogu $V$, De Smet WH, Fontaneto $D$, Jondelius $U$, et al. Patterns of diversity in soft-bodied meiofauna: dispersal ability and body size matter. PLoS One. 2012;7:e33801. 13p.

32. Struck TH, Wey-Fabrizius AR, Golombek A, Hering L, Weigert A, Bleidorn C, et al. Platyzoan paraphyly based on phylogenomic data supports a noncoelomate ancestry of spiralia. Mol Biol Evol. 2014;31:1833-49.

33. Andrade S, Novo M, Kawauchi G, Worsaae K, Pleijel F, Giribet G, Rouse GW: Articulating the "archiannelids": A phylogenomic approach to annelid relationships with emphasis on meiofaunal taxa. Molecular Biology and Evolution 2015, doi:10.1093/molbev/msv157, 16p.

34. Worsaae K, Kristensen RM. Evolution of interstitial Polychaeta (Annelida). Hydrobiologia. 2005:535:319-40.

35. Edgecombe GD, Giribet G, Dunn CW, Hejnol A, Kristensen RM, Neves RC, et al. Higher-level metazoan relationships: recent progress and remaining questions. Org Divers Evol. 2011;11:151-72.

36. Westheide W. Polychaetes: interstitial families. In: Kermack DM, Barnes RSK, editors. Synopsis of the British Fauna, Volume 44. Linnean Society: London; 1990. 152p.

37. Jochová J, Zakeri Z, Lockshin RA. Rearrangement of the tubulin and actin cytoskeleton during programmed cell death in Drosophila salivary glands. Cell Death Differ. 1997:4:140-9.
38. Filippova AV, Purschke G, Tzetlin AB, Müller MCM. Musculature in polychaetes: Comparison of Myrianida prolifera (Syllidae) and Sphaerodoropsis sp. (Sphaerodoridae). Invertebr Biol. 2010;129:184-98.

39. Hooge MD. Evolution of body-wall musculature in the Platyhelminthes (Acoelomorpha, Catenulida, Rhabditophora). J Morphol. 2001;249: 171-94.

40. Faller S, Rother BH, Todt C, Schmidt-Rhaesa A, Loesel R. Comparative neuroanatomy of Caudofoveata, Solenogastres, Polyplacophora, and Scaphopoda (Mollusca) and its phylogenetic implications. Zoomorphology. 2012;131:149-70

41. Redl E, Scherholz M, Todt C, Wollesen T, Wanninger A. Development of the nervous system in Solenogastres (Mollusca) reveals putative ancestral spiralian features. Evodevo. 2014;5:1-17.

42. Beckers P. Nemertean Nervous System - a Comparative Analysis. Germany: Dissertation at the Rheinishe Friedrich-Wilhelms-Universität Bonn; 2012. p. 1-121.

43. Brenzinger B, Haszprunar G, Schrödl M. At the limits of a successful body plan - 3D microanatomy, histology and evolution of Helminthope (Mollusca: Heterobranchia: Rhodopemorpha), the most worm-like gastropod. Frontiers in Zool. 2013;10:37

44. Brenzinger B, Wilson NG, Schrödl M. 3D microanatomy of a gastropod "worm", Rhodope rousei n. sp. (Heterobranchia) from southern Australia. J Molluscan Stud. 2011;77:375-87.

45. Jörger KM, Stoschek T, Migotto A, Haszprunar G, Neusser TP: 3D microanatomy of the mesopsammic Pseudovermis salamandrops Marcus, 1953 from Brazil (Nudibranchia, Gastropoda). Marine Biodiversity 2014:44:327-341.

46. Reuter M, Maule AG, Halton DW, Gustafsson MKS, Shaw C. The organization of the nervous system in Plathelminthes. The neuropeptide Fimmunoreactive pattern in Catenulida, Macrostomida, Proseriata. Zoomorphology. 1995;115:83-97.

47. Zrzavy J. Gastrotricha and metazoan phylogeny. Zool Scr. 2003;32:61-81.

48. Beckers $P$, Loesel R, Bartolomaeus T. The nervous systems of basally branching Nemertea (Palaeonemertea). PLoS One. 2013;8:e66137.

49. Bullock TH, Horridge GA. Structure and function in the nervous system of invertebrates. W. H. Freeman: San Francisco, London; 1965.

50. Bubko OV, Minichev YS. The nervous system of Oweniidae. Zool Zhurnal. 1972:51:1288-99.

51. Lagutenko YP. Structural organization of the nervous plexus in the oweniids (Polychaeta: Oweniidae). Zool Zhurnal. 1985;64:1802-7.

52. Lagutenko YP. Early forms of Evolution of the Basiepidermal nerve Plexus of Bilateria as a Possible Evidence for Primary Diversity of Its Initial State. J Evol Biochem Physiol. 2002;38(3):354-63.

53. Clark RB. The Posterior Lobes of Nephtys - Observations on 3 New England Species. Q J Microsc Sci. 1958;99:505.

54. Golding DW: Polychaeta: nervous system. In Microscopic Anatomy of Invertebrates. Volume 7: Annelida. Edited by Harrison FW, Gardiner SL. New York; 1992:153-179.

55. Purschke G: Structure of the prostomial appendages and the central nervous system in the Protodrilida (Polychaeta). Zoomorphology 1993,113:120 .

56. Goodrich ES: Nerilla an archiannelid. Quarterly Journal of Microscopical Science 1912, 57(4):397-425

57. Wanninger A, Koop D, Bromham L, Noonan E, Degnan BM. Nervous and muscle system development in Phascolion strombus (Sipuncula). Dev Genes Evol. 2005;215:509-18.

58. Mainoya JR. Morphological and histochemical observations on the nervous system of two sipunculid species, Siphonosoma australe and S. cumanense. Mar Biol. 1974;27:275-80

59. Kristof A, Wollesen $T$, Wanninger A. Segmental mode of neural patterning in Sipuncula. Curr Biol. 2008;18:1129-32.

60. Rieger RM, Rieger GE. Fine structure of the archiannelid cuticle and remarks on the evolution of the cuticle within Spiralia. Acta Zool (Stockholm). 1976:5:53-68.

61. Worsaae K, Rouse GW. Is Diurodrilus an Annelid? J Morphol. 2008;269:1426-55.

62. Tolbert LP. Olfactory development in invertebrates. On the scent of central developmental issues. Ann N Y Acad Sci. 1998;855:95-103.

63. Krieger J, Breer $\mathrm{H}$. Olfactory reception in invertebrates. Science. 1999;286:720-3

64. Lewbart GA, Riser NW. Nuchal Organs of the Polychaete Parapionosyllis manca (Syllidae). Invertebr Biol. 1996;115:286-98. 
65. Schmidtberg H, Dorresteijn AWC. Ultrastructure of the nuchal organs in the polychaete Platynereis dumerilii (Annelida, Nereididae). Invertebr Biol. 2010;129:252-65.

66. Purschke G, Hessling R. Analysis of the Central Nervous System and Sense Organs in Potamodrilus fluviatilis (Annelida: Potamodrilidae). Zool Anz. 2002;241(1):19-35.

67. Gould SJ. Ontogeny and phylogeny. Cambridge: Harvard University Press; 1977.

68. Schmidt-Rhaesa A. The Evolution of organ systems. Cambridge: Oxford University Press; 2007.

69. Rieger RM, Purschke $\mathrm{G}$. The coelom and the origins of the annelid body plan. Hydrobiologia. 2005;535(536):127-37.

70. Fischer $\mathrm{AH}$, Henrich $\mathrm{T}$, Arendt D. The normal development of Platynereis dumerilii (Nereididae, Annelida). Frontiers in Zool. 2010;7:31.

71. Wanninger A. Shaping the things to come: ontogeny of lophotrochozoan neuromuscular systems and the Tetraneuralia concept. Biol Bull. 2009:216:293-306.

72. Wanninger A. Morphology is dead - long live morphology! Integrating MorphoEvoDevo and phylogenomics Frontiers in Ecol and Evolution. 2015;3:54.

73. Müller CHG, Hylleberg J, Michalik P. Complex epidermal organs of Phascolion (Sipuncula): insights into the evolution of bimodal secretory cells in annelids. Acta Zool. 2014;96:343-374.

74. Akkesson B. A Study of the Nervous System of the Sipunculoideae with some remarks on the development of the two Species Phascolion strombi Montagu and Golfingia minuta Keferstein. In: Gleerup CWK, editor. Undersökninger over Öresund, Volume 38. Håkan Ohlssons Boktryckeri: Lund; 1958. 250p.

75. Wilkens V, Purschke G. Pigmented eyes, photoreceptor-like sense organs and central nervous system in the polychaete Scoloplos armiger (Orbiniidae, Annelida) and their phylogenetic importance. J Morphol. 2009;270:1296-310.

76. Helm C, Krause A, Bleidorn C. Immunohistochemical investigations of the development of Scoloplos armiger ("intertidalis clade") indicate a paedomorphic origin of Proscoloplos cygnochaetus (Annelida, Orbiniidae). Invertebr Biol. 2015;134(3):214-30.

77. Beckers P, Faller S, Loesel R. Lophotrochozoan neuroanatomy: An analysis of the brain and nervous system of Lineus viridis (Nemertea) using different staining techniques. Frontiers in Zool. 2011;8:1-12.

78. Müller MCM, Sterrer W. Musculature and nervous system of Gnathostomula peregrina (Gnathostomulida) shown by phalloidin labeling, immunohistochemistry, and CLSM, and their phylogenetic significance. Zoomorphology. 2004;123:169-77.

79. Kristensen RM, Nørrevang A. On the Fine Structure of Rastrognathia macrostoma gen. et sp.n. placed in Rastrognathiidae fam.n. (Gnathostomulida). Zool Scripta. 1977;6:27-41.

80. Ruppert EE, Schreiner SP. Ultrastructure and Potential Significance of Cerebral Light-Refracting Bodies of Stenostomum virginianum (Turbellaria, Catenulida). Zoomorphology. 1980;96:21-31.

81. Gustafsson MKS, Raikova OI, Reuter M, Jondelius U. The brain of the Nemertodermatida (Platyhelminthes) as revealed by anti-5HT and anti-FMRFamide immunostainings. Tissue \& Cell. 2000;32(5):358-65.

82 Raikova OI, Reuter M, Gustafsson MKS, Maule AG, Halton DW, Jondelius U. Basiepidermal nervous system in Nemertoderma westbladi (Nemertodermatida): GYIRFamide immunoreactivity. Zoology. 2004;107:75-86.

83. Rieger RM. Jennaria pulchra, nov. gen. nov spec., eine den psammobionten Anneliden nahestehende Gattung aus dem Küstengrundwasser von North Carolina. Berichte des naturwisschenschaftlich-medizinischem Vereins Innsbruck. 1991;78:203-15.

84. Fofanova EG, Nezlin LP, Voronezhskaya EE. Ciliary and nervous structures in juvenile females of the annelid Dinophilus gyrociliatus (O. Schmidt, 1848) (Annelida: Polychaeta). Russ J Mar Biol. 2014;40:43-52.

85. Fofanova EG, Voronezhskaya EE. The structure of archiannelid Dinophilus gyrociliatus ventral nerve cords. Acta Biol Hung. 2012;63:88-90.

86. Merker G, Harnack MV-V. Zur Feinstruktur des Gehirns und der Sinnesorgane von Protodrilus rubropharyngaeus Jaegersten (Archiannelida). Cell Tissue Res. 1967:81:221-39.

87. Nørrevang A, Kristensen RM. Description of Psammodrilus aedificator sp.n. (Polychaeta), with Notes on the Arctic Interstitial Fauna of Disko Island, W. Greenland. 1982;11:265-79.

88. Worsaae K, Sterrer W. Description of two new interstitial species of Psammodrilidae (Annelida) from Bermuda. Mar Biol Res. 2006;2:431-45.
89. Fischer A, Dorresteijn A. The polychaete Platynereis dumerilii (Annelida): a laboratory animal with spiralian cleavage, lifelong segment proliferation and a mixed benthic/pelagic life cycle. BioEssays: news and reviews in molecular, cell and dev biol. 2004;26:314-25.

90. Denes AS, Jekely G, Steinmetz PRH, Raible F, Snyman H, Prud'homme B, et al. Molecular architecture of annelid nerve cord supports common origin of nervous system centralization in bilateria. Cell. 2007;129:277-88.

91. Meyer NP, Seaver EC. Neurogenesis in an annelid: characterization of brain neural precursors in the polychaete Capitella sp. I Dev Biol. 2009;335:237-52.

92. Brinkmann N, Wanninger A. Neurogenesis suggests independent evolution of opercula in serpulid polychaetes. BMC Evol Biol. 2009;9:1-13.

\section{Submit your next manuscript to BioMed Central and take full advantage of:}

- Convenient online submission

- Thorough peer review

- No space constraints or color figure charges

- Immediate publication on acceptance

- Inclusion in PubMed, CAS, Scopus and Google Scholar

- Research which is freely available for redistribution 